\title{
Evaluation of remotely sensed rainfall products over Central Africa
}

\author{
Pierre Camberlin $^{1} \odot$ | Geoffrey Barraud ${ }^{1}$ | Sylvain Bigot ${ }^{2}$ | Olivier Dewitte $^{3}$ | \\ Fils Makanzu Imwangana ${ }^{4}$ | Jean-Claude Maki Mateso ${ }^{5,6}$ | Nadège Martiny ${ }^{1}$ | Elise Monsieurs ${ }^{3,7,8}$ | \\ Vincent Moron ${ }^{9}$ | Thierry Pellarin ${ }^{2}$ | Nathalie Philippon ${ }^{2} \mid$ Muhindo Sahani $^{10}$ | Gaston Samba ${ }^{11}$
}

${ }^{1}$ Centre de Recherches de

Climatologie/Biogéosciences, Université

Bourgogne Franche-Comté, Dijon, France

${ }^{2}$ Institut des Géosciences de

l'Environnement, Université Grenoble

Alpes, Grenoble, France

${ }^{3}$ Royal Museum for Central Africa,

Tervuren, Belgium

${ }^{4}$ Unité de Recherche et de Formation en Gestion des Risques Naturels, Département des Géosciences, Faculté des Sciences, Université de Kinshasa, Kinshasa, DR Congo

${ }^{5}$ Department of Geophysics, Centre de Recherche en Sciences Naturelles, Lwiro, DR Congo

${ }^{6}$ Faculty of Bioscience Engineering \& Earth and Life Institute, Université Catholique de Louvain, Louvain-La-Neuve, Belgium

${ }^{7}$ Department of Geography, University of Liège, Liège, Belgium

${ }^{8}$ F.R.S.-FNRS, Brussels, Belgium

${ }^{9}$ CEREGE, Aix Marseille Univ, CNRS, IRD, INRA, Coll. de France, Aix en Provence, France

${ }^{10}$ Université Catholique du Graben, Butembo, DR Congo

${ }^{11}$ Centre de recherche et d'étude sur l'environnement, Ecole Normale Supérieure, Université Marien Ngouabi, Brazzaville, Republic of Congo

\section{Correspondence}

Pierre Camberlin, Centre de Recherches de Climatologie/Biogéosciences, UMR 6282 CNRS/Université Bourgogne

Franche-Comté, 21000 Dijon, France.

Email: pierre.camberlin@u-bourgogne.fr

\begin{abstract}
An intercomparison of seven gridded rainfall products incorporating satellite data (ARC, CHIRPS, CMORPH, PERSIANN, TAPEER, TARCAT, TMPA) is carried out over Central Africa, by evaluating them against three observed datasets: (a) the WaTFor database, consisting of 293 (monthly records) and 154 (daily records) rain-gauge stations collected from global datasets, national meteorological services and monitoring projects, (b) the WorldClim v2 gridded database, and (c) a set of stations expanded from the FAOCLIM network, these two latter sets describing climate normals. All products fairly well reproduce the mean rainfall regimes and the spatial patterns of mean annual rainfall, although with some discrepancies in the east-west gradient. A systematic positive bias is found in the CMORPH product. Despite its lower spatial resolution, TAPEER shows reasonable skills. When considering daily rainfall amounts, TMPA shows best skills, followed by CMORPH, but over the central part of the Democratic Republic of the Congo, TARCAT is amongst the best products. Skills ranking is however different at the interannual time-scale, with CHIRPS and TMPA performing best, though PERSIANN has comparable skills when only fully independent stations are used as reference. A preliminary study of Southern Hemisphere dry season variability, from the example of Kinshasa, shows that it is a difficult variable to capture with satellite-based rainfall products. Users should still be careful when using any product in the most data-sparse regions, especially for trend assessment.
\end{abstract}

\section{KEYWORDS}

Precipitation, Remote sensing, Congo Basin, DRC, Central African Republic, Cameroon, Gabon 


\section{INTRODUCTION}

Although an important region for the huge carbon stock contained in its forests (Lewis et al., 2009; Saatchi et al., 2011; Verhegghen et al., 2012), Central Africa is still poorly documented in terms of climate change and climate variability. An important explaining factor is the scarcity of in situ observations available, even compared to other African regions (Malhi et al., 2013). Meteorological networks, already characterized by a low density of stations in the 1960s and 1970s, have been gradually deteriorating since then (Maloba Makanga, 2009; Washington et al., 2013; Nicholson et al., 2018). For instance, in the early 2010 s, no station reports were received any more in the Global Telecommunication System from most of the Democratic Republic of the Congo (DRC), which covers over 2 million $\mathrm{km}^{2}$. Therefore, in order to properly describe the rainfall patterns, trends and variability over recent decades in Central Africa, the use of precipitation estimates from satellite observations is crucial. A large number of near-global, gridded rainfall datasets based on, or incorporating, satellite data are now available. However, the skills of these datasets need to be assessed regionally and at different time-scales. Heaney et al. (2016) inventoried the sources of meteorological data used to study the interactions between weather and infectious diseases in Central Africa. They noted that due to sparse and intermittent ground-based observations, gauge-only interpolated datasets in Central Africa do not contain adequate information for local-scale analyses, although researchers use them regularly. Zhou et al. (2014) and Hua et al. (2016) found strong decreasing trends in April-June rainfall over the northern part of DRC since the late 1990s, in two global-scale datasets merging satellite and rain-gauge data. However, Maidment et al. (2015) obtained striking differences in Central Africa de-seasonalised precipitation trends between 1983 and 2010 depending on the gridded dataset, especially a suspicious rainfall decline in the ARC product, which they attributed to temporally inconsistent and sparse gauge networks.

Only a small number of studies have been dedicated to the intercomparison between satellite rainfall estimates over Central Africa, and very few have included a validation step against in situ observations. McCollum et al. (2000) analysed an early version of GPCP (Global Precipitation Climatology Project) satellite estimates showing that in Central Africa annual rainfall estimates had approximately twice the magnitude of those obtained from rain-gauges. Beighley et al. (2011), through streamflow data and a river routing model, found that satellite rainfall estimates provide unreasonably high values during the rainy seasons, although TMPA (sometimes referred to as TRMM in the literature) outperforms CMORPH and PERSIANN (see Table 1 for a listing of satellite-derived precipitation datasets). Washington et al. (2013) compared a number of satellite rainfall estimates
(CMAP, TAMSAT, GPCP, CMORPH, TMPA) with gridded, gauge-only observations (Climate Research Unit - CRU), reanalysis data and outputs from CMIP3 and CMIP5 models. Their analysis however considered neither interannual variability nor the daily time-scale. They found inconsistencies (including between the observational datasets) in the location of mean annual precipitation maxima over the Congo Basin. Vondou and Haensler (2017) assessed the skill of the regional climate model REMO against various gridded observation or satellite products. They noted that regarding interannual variations, a large spread is found among observations, highlighting uncertainties related to the very low density of stations. Major differences are also found between TMPA and GPCP in the wet-day frequency and the 95th percentile of daily rainfall. Munzimi et al. (2015) found relatively large biases in TMPA over the Congo Basin. However, a recalibrated version of the product using 12 rain-gauges from DRC performs better, as based on a validation against the WorldClim long-term mean precipitation field. Monsieurs et al. (2018) validated TMPA over the western branch of the East African Rift against 46-gauge observations from 1998 to 2018. They found a systematic underestimation of TMPA for rainfall above $5 \mathrm{~mm} /$ day, and a lower performance during the dry months and in areas with complex topography.

Other intercomparison or validation studies were carried out at continental scale or considering several regions across Africa. Thiemig et al. (2012) analysed CMORPH, RFE v2, TMPA, PERSIANN, GSMap products as well as ERA-Interim over four sparsely gauged African river basins (Zambezi in Southern Africa, Volta in West Africa, Juba-Shabelle in East Africa and Baro-Akobo in Ethiopia). The validation against 205 rain-gauge stations focused on rainfall characteristics relevant to hydrological applications, such as annual catchment totals, spatial patterns, seasonality, number of rainy days, timing and volume of heavy rainfall events. On the whole, RFE v2 and TMPA tended to be the most accurate. Sylla et al. (2013) intercompared daily rainfall from three observed datasets incorporating satellite data (TMPA, RFE v2 and GPCP) over Africa as a whole. Small differences were found in mean rainfall, but larger ones in higher-order daily precipitation statistics, such as frequency of wet days, precipitation intensity, extremes and maximum length of wet and dry spells. These differences between observational datasets prevent an unambiguous evaluation of numerical climate models over Africa. Awange et al. (2016) compared six satellite rainfall products at monthly time-scale over Africa. Via a multiple comparison ranking, and by taking GPCC (Global Precipitation Climatology Centre) data over entire Africa and rain-gauge observations over the Greater Horn of Africa as references, it was found that PERSIANN had the highest signal-to-noise ratio, followed by ARC v2, TMPA, CMORPH, TAMSAT and GSMaP. A similar 
T A B L E 1 Inventory of satellite rainfall estimates datasets listed in the literature review or used in the study (upper part of the table)

\begin{tabular}{|c|c|c|c|c|c|}
\hline Dataset & Full name & Reference & $\begin{array}{l}\text { Spatial } \\
\text { resolution }\end{array}$ & $\begin{array}{l}\text { Time-scale } \\
\text { (highest } \\
\text { resolution) }\end{array}$ & $\begin{array}{l}\text { Period of } \\
\text { availability } \\
\text { (in brackets, } \\
\text { period used) }\end{array}$ \\
\hline \multicolumn{6}{|c|}{ Datasets used in the present study (stars denote products which are adjusted with observed rainfall data) } \\
\hline ARC v2 (*) & $\begin{array}{l}\text { Africa Rainfall Climatology } \\
\text { version } 2.0\end{array}$ & Novella and Thiaw (2013) & $0.10^{\circ}$ & Daily & $\begin{array}{l}\text { 1983-Present } \\
(1983-2017)\end{array}$ \\
\hline CHIRPS v2 $(*)$ & CHIRP with station data & Funk et al. (2015) & $0.05^{\circ}$ & Daily & $\begin{array}{l}\text { 1981-Present } \\
(1983-2017)\end{array}$ \\
\hline CMORPH & $\begin{array}{l}\text { Climate Prediction Center } \\
\text { morphing technique }\end{array}$ & Joyce et al. (2004) & $0.07^{\circ}$ & Half-hourly & $\begin{array}{l}\text { 12/2002-Present } \\
(2003-2017)\end{array}$ \\
\hline PERSIANN (*) & $\begin{array}{l}\text { Precipitation Estimation from } \\
\text { Remotely Sensed Information } \\
\text { using Artificial Neural Networks }\end{array}$ & Ashouri et al. (2015) & $0.25^{\circ}$ & $\begin{array}{l}\text { Daily } \\
\text { (PERSIANN- } \\
\text { CDR) }\end{array}$ & $\begin{array}{l}\text { 1983-Present } \\
(1983-2017)\end{array}$ \\
\hline $\begin{array}{l}\text { TAMSAT / } \\
\text { TARCAT v3 }\end{array}$ & $\begin{array}{l}\text { Tropical Applications of } \\
\text { Meteorology using SATellite data } \\
\text { and ground-based observations } \\
\text { African Rainfall Climatology And } \\
\text { Time series }\end{array}$ & Maidment et al. (2017) & $0.0375^{\circ}$ & Daily & $\begin{array}{l}\text { 1983-Present } \\
(1983-2017)\end{array}$ \\
\hline TAPEER & $\begin{array}{l}\text { Tropical Amount of Precipitation } \\
\text { with an Estimation of Errors }\end{array}$ & Chambon et al. (2013) & $1^{\circ}$ & 6-hourly & $\begin{array}{l}10 / 2011-2016 \\
(2011-2016)\end{array}$ \\
\hline $\begin{array}{l}\text { TMPA 3B42 } \\
\text { v7 (*) }\end{array}$ & $\begin{array}{l}\text { Tropical Rainfall Measuring } \\
\text { Mission (TRMM) Multi-satellite } \\
\text { Precipitation Analysis }\end{array}$ & Huffman et al. (2007) & $0.25^{\circ}$ & 3-hourly & $\begin{array}{l}\text { 1998-Present } \\
(1998-2014)\end{array}$ \\
\hline \multicolumn{6}{|c|}{ Datasets not used in the present study } \\
\hline CHIRP & $\begin{array}{l}\text { Climate Hazards group InfraRed } \\
\text { Precipitation }\end{array}$ & Funk et al. (2015) & $0.05^{\circ}$ & Daily & 1981-Present \\
\hline CMAP & $\begin{array}{l}\text { CPC Merged Analysis of } \\
\text { Precipitation }\end{array}$ & Xie and Arkin (1997) & $2.5^{\circ}$ & Pentad & 1979-Present \\
\hline GPCP 1DD & $\begin{array}{l}\text { Global Precipitation Climatology } \\
\text { Project one-Degree Daily }\end{array}$ & Adler et al. (2012) & $1^{\circ}$ & Daily & 1996-Present \\
\hline GSMaP & $\begin{array}{l}\text { Global Satellite Mapping of } \\
\text { Precipitation }\end{array}$ & Kubota et al. (2007) & $0.10^{\circ}$ & Hourly & $2002-2010$ \\
\hline IMERG & $\begin{array}{l}\text { Integrated Multi-satellitE } \\
\text { Retrievals for Global precipitation } \\
\text { measurement }\end{array}$ & Huffman et al. (2015) & $0.10^{\circ}$ & Half-hourly & 03/2014-Present \\
\hline RFE v2 & $\begin{array}{l}\text { Climate Prediction Center (CPC) } \\
\text { African RainFall Estimates }\end{array}$ & Love et al. (2004) & $0.10^{\circ}$ & Daily & 2001-Present \\
\hline
\end{tabular}

intercomparison, taking into account a smaller number of datasets but at a finer temporal resolution (daily) was carried out by Serrat-Capdevila et al. (2016). TMPA was found to have the smallest bias in Central Africa compared to the other products, underestimating daily rainfall on average by less than $10 \%$, and PERSIANN has the smallest median errors of rainfall amounts when it correctly detects precipitation events. Maidment et al. (2017) assessed the skill of two versions of the TAMSAT product over Africa by comparing them with CHIRP, CHIRPS, ARC v2, RFE v2, TMPA, CMORPH as well as rain-gauges in five countries. The TAMSAT daily estimates improve on the detection of rainy days (based on a $0 \mathrm{~mm}$ threshold) but have no more skill than the other datasets in capturing rainfall amounts. Several studies focused on a single African subregion or country, e.g. Uganda (Maidment et al., 2012; Diem et al., 2014; 2019), the Zambezi Basin (Cohen Liechti et al., 2012), West Africa (Gosset et al., 2013; 2018), Angola (Pombo et al., 2015), East Africa (Dinku et al., 2018), or the Ethiopian Rift Valley (Tesfamariam et al., 2019), among others.

On the whole, these studies show that (a) there are significant disparities in the skill of the satellite rainfall estimates, 
(a)

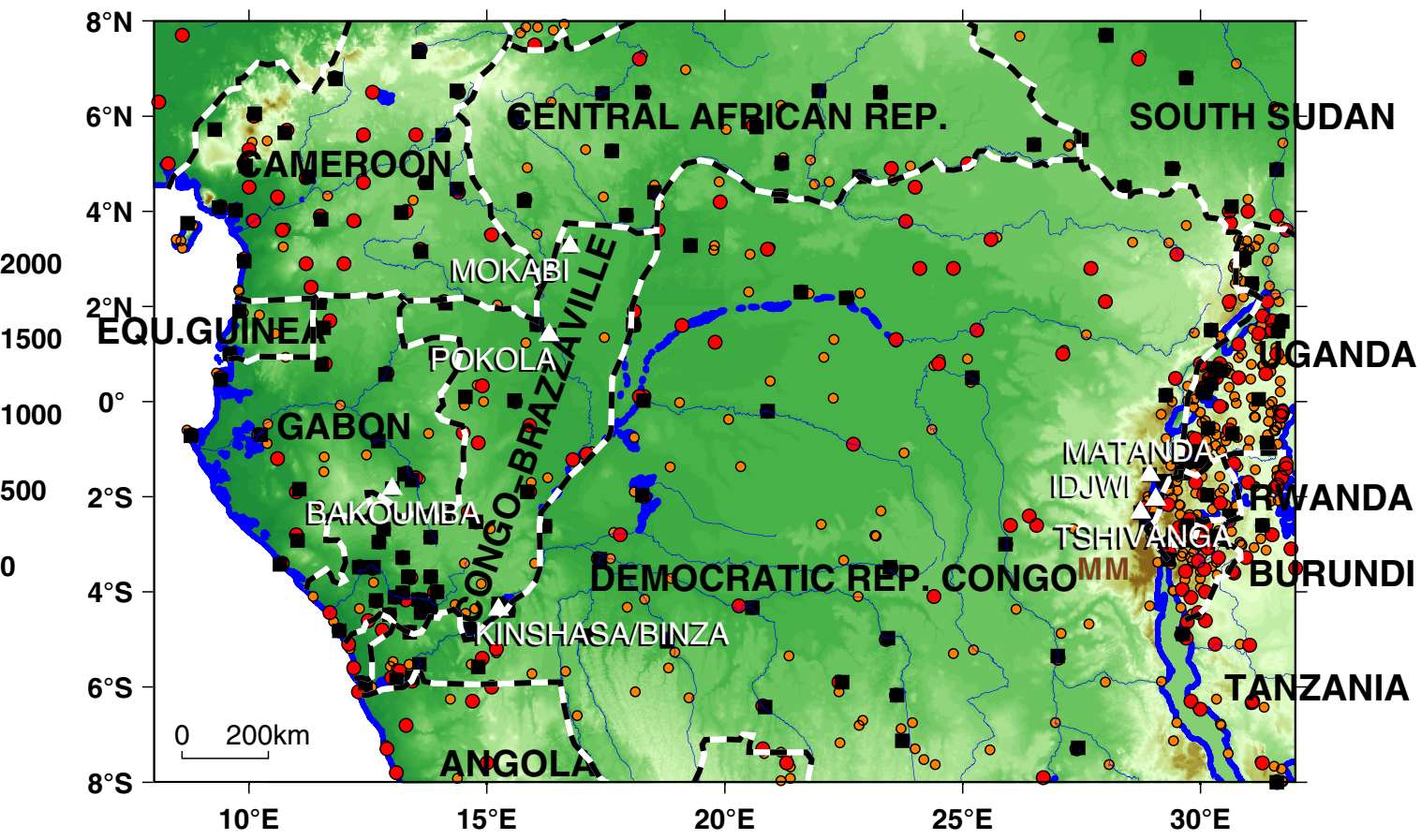

(b)

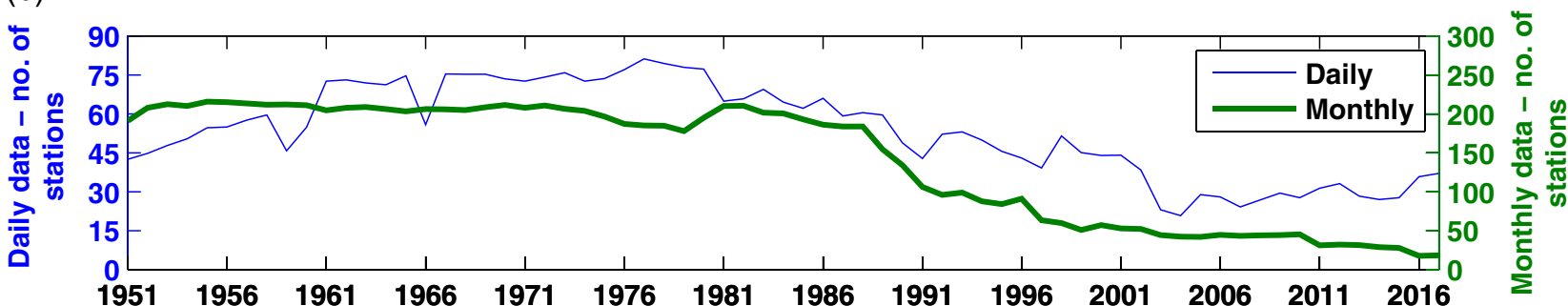

F I G U R E 1 Data availability in the WatFOR database. (a) Location map and network of stations; (b) variations in the total number of stations available for each month. In (a), black squares denote stations of the daily database, large red dots stations of the monthly database. Small orange dots show additional stations having long-term mean monthly records (FAOCLIM and CRC datasets). White triangles are reference stations for special analyses (see text). Shadings show elevations in metres. MM: Mitumba Mountains [Colour figure can be viewed at wileyonlinelibrary.com].

(b) there is no single best product, the skill of the products being dependent on the rainfall variable considered, and (c) the choice of the best product is highly dependent on the application (Dembélé and Zwart, 2016). Although some products do show recurrent skills or biases, there are important differences from region to region, and their performance also depends on the time-scale. This highlights the need for a comprehensive assessment over Central Africa, whose climate conditions are quite different from those of neighbouring African regions and where based on the few prior studies significant biases seem to be found in many satellite products. Therefore, the present study seeks to assess the skill of seven different satellite rainfall estimates for Central Africa, by considering a range of validation statistics and time-scales, from daily to monthly means and interannual variability. An additional evaluation is carried out of how the products are able to document the length of the dry season, which is viewed as an important parameter for forest dynamics in the context of climate change (Fu et al., 2013; Boisier et al., 2015).
The analysis considers Central Africa as the region extending $8^{\circ} \mathrm{S}-8^{\circ} \mathrm{N}, 8-32^{\circ} \mathrm{E}$ centred on the Congo rainforest. This region encloses most of Cameroon and the Central African Republic (CAR), except their northernmost parts, Equatorial Guinea, Gabon, the Republic of the Congo (Congo-Brazzaville), most of DRC (except its southernmost part), Rwanda, Burundi, and the westernmost parts of Uganda and Tanzania (Figure 1).

Section 2 presents the satellite and observational datasets used in the study. The methods and the issues related to the datasets intercomparison are discussed in section 3 . The results are framed around five aspects: mean annual rainfall (section 4.1), mean monthly regimes (section 4.2), daily rainfall (section 4.3), interannual variations (section 4.4), and dry season length (section 4.5).

\section{$2 \mid$ DA TA}

\section{1 $\quad$ Satellite products}

Seven satellite rainfall estimates have been selected for intercomparison (Table 1). Because of the paucity of 
recent rain-gauge validation data, we prioritized datasets covering a long period of time (from the 1980s), but other datasets available over shorter periods (from the late 1990s or early 2000s) are also included for comparison. They all have a high resolution in time (at least daily time-scale) and their spatial resolutions range from 0.0375 to $0.25^{\circ}$. TAPEER is an exception with its horizontal resolution of $1^{\circ}$ square but this 6-hourly dataset is a fairly new product based on the Megha-Tropiques satellite mission launched in October 2011, and which has seldom been included in previous assessment studies dedicated to African precipitation. The present study should by no means be considered as an intercomparison of all existing satellite precipitation products. Several datasets, or versions of datasets (e.g. real-time products against long-term products) are not included. For instance, we did not use RFE2, an operational product available since 2001, but did use ARC v2. The latter, available since 1983, is based on the same algorithm as RFE2 but uses a subset of the inputs used in RFE2, and a three-hourly temporal sampling of infrared temperatures as opposed to the half-hourly sampling used in RFE2 (Novella and Thiaw, 2013). The spatial and temporal resolutions, periods of data availability and references of the seven products retained are presented in Table 1. The following description summarizes the basic methodology followed to obtain these products. Note that some products (stars in Table 1) include a merging with gridded rain-gauge observations, generally at a monthly time-scale.

The ARC v2 product (Novella and Thiaw, 2013) provides long-term daily rainfall estimates based on a combination of 3-hourly Meteosat geostationary infrared images and rain-gauge observations from the Global Telecommunication Systems (GTS). It uses the GOES Precipitation Index (GPI) algorithm, i.e. the calculation of the daily fractional coverage of cloud-top temperatures below $235 \mathrm{~K}$, multiplied by a rain-rate constant of $3 \mathrm{~mm} \mathrm{~h}^{-1}$. Biases are reduced by merging the satellite estimates with gridded rain-gauge data.

CHIRPS (Funk et al., 2015) is another long-term rainfall product, which is produced in two steps. The first step (CHIRP product) uses infrared images with the same cloud-top temperature threshold as in ARC v2, but calibrates rainfall estimates using (a) another precipitation estimate (TMPA, see below), which incorporates radar and microwave data, over a shorter period of time (2000-2013), and (b) a long-term high-resolution rain-gauge climatology. In the second step, CHIRP estimates are merged with daily rain-gauge records.

CMORPH (Joyce et al., 2004) is a rainfall estimate based on passive microwave data from low-orbit satellites. Motion vectors are determined from half-hourly geostationary infrared images and used to propagate the estimates obtained from the microwave data. The rainfall estimates are not merged with any rain-gauge observations.
PERSIANN precipitation estimates are obtained by applying neural network functions to infrared brightness temperature from the geostationary satellites. The PERSIANN-CDR long-term product (Ashouri et al., 2015) used in the present study adjusts the estimates to monthly gridded rain-gauge data from GPCP.

TAMSAT rainfall products are based on computing cold-cloud duration (CCD) from Meteosat infrared images at time steps of 15 and $30 \mathrm{~min}$. Calibration with historical rain-gauge data is carried out at regional scale and in two steps: rainfall occurrence is mapped by determining optimal cloud temperature thresholds, then five-day (pentadal) rainfall amounts are estimated by a linear regression of CCD against gauge data. Daily rainfall estimates are obtained by dividing pentadal accumulations by the pentadal CCD then multiplying by the daily CCD. The TAMSAT rainfall product used in this study, TARCAT v3.0 (TAMSAT African Rainfall Climatology And Time-series: Maidment et al., 2017), is based on calibrations which do not change from year to year, and does not merge any near-real-time rain-gauge observations. This was in order to have a consistent dataset in time and space, free from artefacts related to changes in the network of rain-gauges.

TAPEER is a recently released daily rainfall estimate which incorporates passive microwave data from several low-orbit satellites, and infrared data from geostationary satellites (Chambon et al., 2013). It adapts the standard GPI criteria to current and local meteorological conditions. The present study retains a version of TAPEER which includes data from the Megha-Tropiques SAPHIR microwave sounder, and a bias correction scheme based on TRMM precipitation radar climatology (Gosset et al., 2018; Roca et al., 2018). In Niger and Burkina Faso, TAPEER exhibits very small biases in the reproduction of the frequency distribution of rain rates (Gosset et al., 2018).

The TMPA 3B42 product (Huffman et al., 2007) incorporates precipitation radar and microwave measurements from the TRMM satellite, which enables us to better evaluate rainfall intensity compared to products using solely infrared data. It combines these data with polar-orbiting and geostationary satellite images to obtain 3-hourly rainfall estimates. The monthly aggregations of rainfall estimates are then scaled to match GPCP monthly gauge analyses. Version 7 used in this study improves upon previous ones by incorporating additional microwave and infrared data, revising the relationship between radar reflectivity and rainfall rates, and using better reference databases for bias correction. We used this product from 1998 to 2014 in order to avoid any possible temporal inhomogeneity related to the decommissioning of TRMM.

\section{2 $\quad$ Observational rainfall datasets}

Three datasets are used for reference: (a) the WaTFor database, an in situ monthly and daily station database 
T A B L E 2 Observed rainfall datasets used for validation

\begin{tabular}{|c|c|c|c|c|}
\hline Dataset & Full name / producer & Reference & Time-scale & Period used \\
\hline $\mathrm{CRC}(*)$ & $\begin{array}{l}\text { Centre de Recherches de } \\
\text { Climatologie / Université } \\
\text { Bourgogne Franche-Comté }\end{array}$ & $\begin{array}{l}\text { Bigot et al. (1997), } \\
\text { Camberlin et al. (2001) }\end{array}$ & Daily / monthly & $1951-2017$ \\
\hline FAOCLIM 2.0 & $\begin{array}{l}\text { Food and Agriculture } \\
\text { Organization }\end{array}$ & FAO (2001) & Long-term monthly means & Various periods \\
\hline $\operatorname{GHCN}(*)$ & $\begin{array}{l}\text { Global Historical Climate } \\
\text { Network / NOAA }\end{array}$ & $\begin{array}{l}\text { Menne } \text { et al. (2012), } \\
\text { Peterson and Vose (1997) }\end{array}$ & Daily / monthly & $1951-2017$ \\
\hline GSOD $(*)$ & $\begin{array}{l}\text { Global Summary Of the Day / } \\
\text { NOAA }\end{array}$ & Lott et al. (2008) & Daily & Mainly 1973-2017 \\
\hline WorldClim v2 & University of California Davis & Fick and Hijmans (2017) & Long-term monthly means & $\begin{array}{l}\text { Representative of the } \\
\text { period 1970-2000 }\end{array}$ \\
\hline
\end{tabular}

Note: The datasets shown with a star, as well as isolated stations described in the text, are included in the "WaTFor" database.

elaborated for the project, (b) the FAOCLIM long-term mean monthly station dataset from the FAO (Food and Agriculture Organization), and (c) the WorldClim long-term mean monthly gridded dataset, version 2 . These datasets are described below. Other available gridded datasets (e.g. CRU or GPCC), although they depict interannual variability, were not retained since they rely on a small number of stations over Central Africa. Gridded time-series therefore merely reflect an interpolation of very distant rainfall data, which is all the more problematic in this region where inter-station correlations steeply decrease with distance (Camberlin et al., 2011).

In the WaTFor database we first combined rainfall records from the Global Historical Climate Network (GHCN), Global Summary Of the Day (GSOD) and Centre de Recherches de Climatologie (CRC) datasets (see Table 2 for description and references). When combining these data, a careful selection was made to avoid duplicates, verify and correct the stations' geographical coordinates, and check the quality of the data by a routine detection of outliers. CRC data mainly come directly from National Meteorological Services and were supplemented by the GHCN and GSOD data (the latter consisting of stations reporting in the GTS), in this order. Careful inspection revealed that raw $24 \mathrm{~h}$ GSOD totals generally lag observations from the National Meteorological Services by 1 day. The standard practice for daily rainfall is to record it at 0600 UTC and to assign the total amount to the preceding day (WMO, 2009). This is apparently not done for the raw GSOD records, which have therefore been reallocated to the preceding day.

Additional daily rainfall time-series have been collected and incorporated in the WaTFor database, namely the stations of Butembo, northeastern DRC (Sahani et al., 2012), Kinshasa/Ndjili and Kinshasa/Binza, DRC (Makanzu et al., 2014), a few stations with shorter records over the central parts of DRC, the synoptic stations of CAR until the early 2000s (included in global databases but with many gaps:
Ndjendolé and Pérard, 2003) and a number of synoptic stations and simple rain-gauges in Congo-Brazzaville (Samba and Nganga, 2012).

Original hourly/sub-hourly rainfall data from six automated tipping-bucket rain-gauges were also collected and transformed in daily accumulations. This includes:

1. Two stations in the northern Republic of the Congo (Pokola and Mokabi), set up by CIRAD (Centre de coopération internationale en recherche agronomique pour le développement) and IGE (Institut des Géosciences de l'Environnement) in March 2016 within two timber forest plots in the framework of the DynAfFor project (Dynamics of African Forests).

2. Three stations in the eastern DRC (Idjwi, Tshivanga and Matanda), as part of the RESIST project (Remote Sensing and In Situ detection and Tracking of geohazards) coordinated by the Royal Museum for Central Africa in Belgium (Monsieurs et al., 2018).

3. One station in Gabon, supervised by CNRS (Centre National de la Recherche Scientifique) at Bakoumba in the Lékédi Natural Park as part of the Mandrillus project.

Data from these automated stations embrace at least the year 2016 with extensions to earlier or later years at some stations. A careful visual and automated inspection of the data was performed to detect errors. For short periods of time, some gauges happened to be blocked by fallen debris, which resulted in rhythmic occurrences of very low amounts. Data from these periods have been deleted.

The final WaTFor database comprises 293 stations for the monthly records and 154 stations for the daily records (mostly a subset of the monthly network) (Figure 1a). The station density is highly variable, with the least stations in most of DRC, especially for the daily records. Some areas of higher densities of stations are found in southwestern Congo-Brazzaville, and in the regions bordering eastern DRC (Burundi, Rwanda, 
western Uganda). Although the period retained is 1951-2017, most stations have much shorter records. For instance, only $57 \%$ of the stations have more than 30 years of monthly records. From an average of 200 stations between the 1950s and the early 1980s for the monthly records (Figure 1b), the number of stations sharply declines at the beginning of the 1990s, with no more than 35-50 stations in the 2000s. Almost no data at all are available over large parts of DRC since the mid-1990s. The daily records exhibit a similar variation, with at least 60 stations every day in the years 1961-1990, dropping to about 20 in the mid-2000s but rising to about 30 stations in the mid-2010s.

For evaluating the spatial patterns of long-term monthly mean precipitation, we also use the FAOCLIM 2.0 global station database assembled by the Food and Agriculture Organization (FAO, 2001). It includes 28,100 stations at the global scale with climate normals computed over various periods, most of the time within the period 1961-1990. Stations located over Central Africa $(N=571)$ have been extracted and completed by additional ones from the CRC database, mostly for the eastern part of the region. Ngoundi station, at the border between Cameroon and CAR, has been removed from the FAOCLIM data due to faulty data (Ouédraogo et al., 2016). Altogether, 641 stations are retained for Central Africa, with a minimum number of 10 years to compute the mean monthly and annual averages (with 54\% of the stations having at least 25 years). Many of these stations are located in relatively data-void areas in the monthly and daily databases, hence the importance of considering this additional dataset. As emphasized by Fick and Hijmans (2017), adding stations in remote locations, even if the temporal sampling of the data is imperfect, brings a contribution to our climate knowledge which is much higher than the possible error associated with the small sample of years or the different period used in computing mean rainfall.

In addition to the WatFor and FAOCLIM databases which consist of rain-gauges only, we used the monthly gridded precipitation data (long-term means) from WorldClim version 2 (Fick and Hijmans, 2017). This database interpolates at an approximately $1 \mathrm{~km}^{2}$ resolution climate station normals from several datasets (including GHCN and FAOCLIM 2.0) using a thin-plate smoothing with covariates such as elevation to produce monthly mean rainfall fields. These fields are representative of the period 1970-2000. However, in data-void areas, they incorporate stations whose climatic averages are computed over other periods (of at least 10 years) without exact temporal range information available (Fick and Hijmans, 2017). Hence, reservations should be made on the blind use of this database when it is compared with more recent data. However, since the network of stations used in constructing this database is much larger than that used in other gridded products (e.g. Ward et al., 2011), WorldClim can be seen as a useful tool (though not perfect) to evaluate the spatial patterns of satellite products over Central Africa. WorldClim (v1) precipitation fields were used as a reference by Munzimi et al. (2015) to assess the skill of TMPA data. Despite the fact that some of the records incorporated in WorldClim are ancient (for DRC, many date back to the colonial period), authors argue that the basin-wide coverage of WorldClim affords a valuable basis for an intercomparison with satellite products. Mean annual rainfall from WorldClim compares very well with Bultot's map (Bultot, 1971) computed from about 500 rain-gauges in the Congo Basin for the period 1930-1959.

\section{3 | METHODS}

The intercomparison between the satellite rainfall estimates and the reference data is based on standard statistics (Ebert, 2007), namely:

- A bias indicator (BIAS, taken as the mean error).

- The root-mean square error (RMSE, which is the square-root of the average of squared errors, and hence is sensitive to outliers).

- Pearson's correlation coefficient (r, showing how well the estimates and the observations covariate in time or in space).

For daily rainfall, correlations are computed using square-root transformed data in order to reduce the skewness in the distribution of the daily rainfall amounts. We use three additional criteria for evaluating daily rainfall occurrence (Wilks, 2011):

- The probability of detection ( $\mathrm{POD}$, or hit rate, which is the number of correctly detected wet days, receiving at least $1 \mathrm{~mm}$, divided by the total number of wet days in the reference dataset).

- The false-alarm ratio (FAR, which is the number of wet estimates while the day is actually dry, divided by the total number of wet estimates).

- The Heidke skill score (HSS, a synthetic skill score which reaches 1 for perfect estimates and is below zero when estimates are not better than random chance).

Analyses consider both the temporal and spatial patterns. The following variables are examined: long-term annual and monthly means, daily variations, interannual variability of monthly rainfall anomalies, and dry season duration. While many of these variables are standard when evaluating rainfall products, dry season duration was additionally investigated because this variable is key in determining the rainforest bioclimate (Fu et al., 2013) and it is believed to bring an added value in evaluating the skill of the products at different time-scales. 
All the satellite rainfall estimates were re-gridded to the $0.05^{\circ}$ resolution via bilinear interpolation, in order to enable an intercomparison of the products. Comparisons with rain-gauge data were carried out by selecting the $0.05^{\circ}$ grid-point nearest to each station. There is a scale mismatch issue between the point-based rain-gauge data and the gridded precipitation products (Tang et al., 2018). For this reason, kriging of in situ rainfall observations prior to evaluation is usually strongly recommended (Roca et al., 2010; Maidment et al., 2012). No interpolation or kriging of the rain-gauge data is carried out in this study because interpolation aims at reducing local noise, but it introduces uncertainty associated with the interpolation method. This is particularly the case in Central Africa where available stations are scarce, making the reliability of kriging or other interpolation disputable. Additionally, the aim is not to rigorously quantify the local skill but to compare the skills of different products. Note that several other studies, especially in regions showing a low density of stations, similarly carried out a direct comparison between rain-gauges and the nearest grid-point (e.g. Buarque et al., 2011; Scheel et al., 2011; Maussion et al., 2014; Engel et al., 2017; Wehbe et al., 2017). Engel et al. (2017) also investigated the impact of increasing numbers of stations in grid cells of varying size.

In order to assess to what extent the scale mismatch between station and gridded data may affect the skill statistics, a comparison was made between long-term monthly mean rainfall at all stations having at least 20 years of data and the nearest WorldClim grid point (re-gridded to $0.05^{\circ}$ resolution). Two hundred and two stations are used in the comparison. The overall correlation ( $n=202 \times 12$ months) is very high $(\mathrm{r}=0.98)$, and the average bias very low $(0.2 \%)$; however, there is a substantial RMSE $(16.8 \mathrm{~mm} /$ month$)$. This could be partly seen as the error resulting from the spatial scale mismatch, and it can be used as a rough benchmark when evaluating the skill scores obtained for the satellite rainfall estimates. However, RMSE also includes errors related to potential mismatches in the time-periods in each dataset, especially the fact that several records dating back to pre-1983 are included in the WorldClim database. A proper evaluation of the spatial scale mismatch should involve considering grid boxes containing several rain-gauges (Monsieurs et al., 2018), but which in the present case is not possible since only one grid box meets this requirement.

Another problem is the uneven length of the rain-gauge time series when analysing the inter-daily or interannual variability. It was not possible to retain a common period across all stations, which would have resulted in the loss of either valuable stations in low-density zones or the loss of all years since about 1990, which is impractical to validate rainfall products starting in more recent years. It was decided that the overall statistics would be computed on all available observations, similar to the approach adopted in Monsieurs et al.
(2018). A minimum number of 100 daily records and 60 monthly records ( 5 years of data) was set for a station to be included in the evaluation. Since the amount of data available strongly varies between stations, and to have a proper view of the spatial variations in the skills of the products, an alternative analysis of interannual variations was conducted in which correlations between rain-gauge time series and those of the nearest grid point were computed by randomly selecting 100 times a fixed number of observations (here 30 months) at each station. Correlations between rain-gauge and satellite estimates (after removing the mean annual cycle) were computed for each of these 100 samples, for the median correlation to be evaluated.

For the statistics computed over the whole set of stations together, a note of caution must also be exerted on the spatial representativeness of the results. Except for long-term means, based on a relatively homogenous distribution of stations and a gridded observation product (WorldClim), statistics computed on the whole dataset (daily and interannual variations) are somewhat biased towards the western part of the region (Gabon, Congo-Brazzaville, CAR), and its easternmost part (around western Uganda).

While it is desirable to use fully independent data in the evaluation of satellite estimates, as pointed out by Scheel et al. (2011), the difficulty in tracing back the exact stations used in the satellite products for the ground calibration and in the merging process (for some products) is a drawback for any verification. Most products incorporating ground observations use GTS stations only which constitute the GSOD database. However over Central Africa GTS stations show a very low density and report intermittently. CHIRPS uses more rain-gauge data, but over countries such as the DRC, the number of monthly observations incorporated fell to near zero at the beginning of the 1990s, and remained low in most neighbouring countries over the same period (Funk et al., 2015). In the present study, an important part of the reference databases can be considered as independent from the satellite rainfall estimates which are evaluated. In addition, two strategies are adopted to evaluate the products against fully independent data at a daily time-scale. First, in a similar way as in Toté et al. (2015), a subset of the rain-gauge data is extracted comprising (a) all stations not included in the GSOD database, and (b), for stations included in GSOD, only the days belonging to months for which no GSOD data at all is available. In total, this subset is made of 83 stations with at least 100 daily records (generally several thousand per station), representing in all more than 225,000 daily records over the period 1983-2017. These stations (Figure 2) are mainly located in southern Congo-Brazzaville, in CAR, near the eastern border of DRC, plus a few stations in central DRC. Since these four subregions have quite distinct rainfall regimes, they will be analysed separately (see boxed areas in Figure 2). Second, a distinct comparison is presented for a recent period of time 


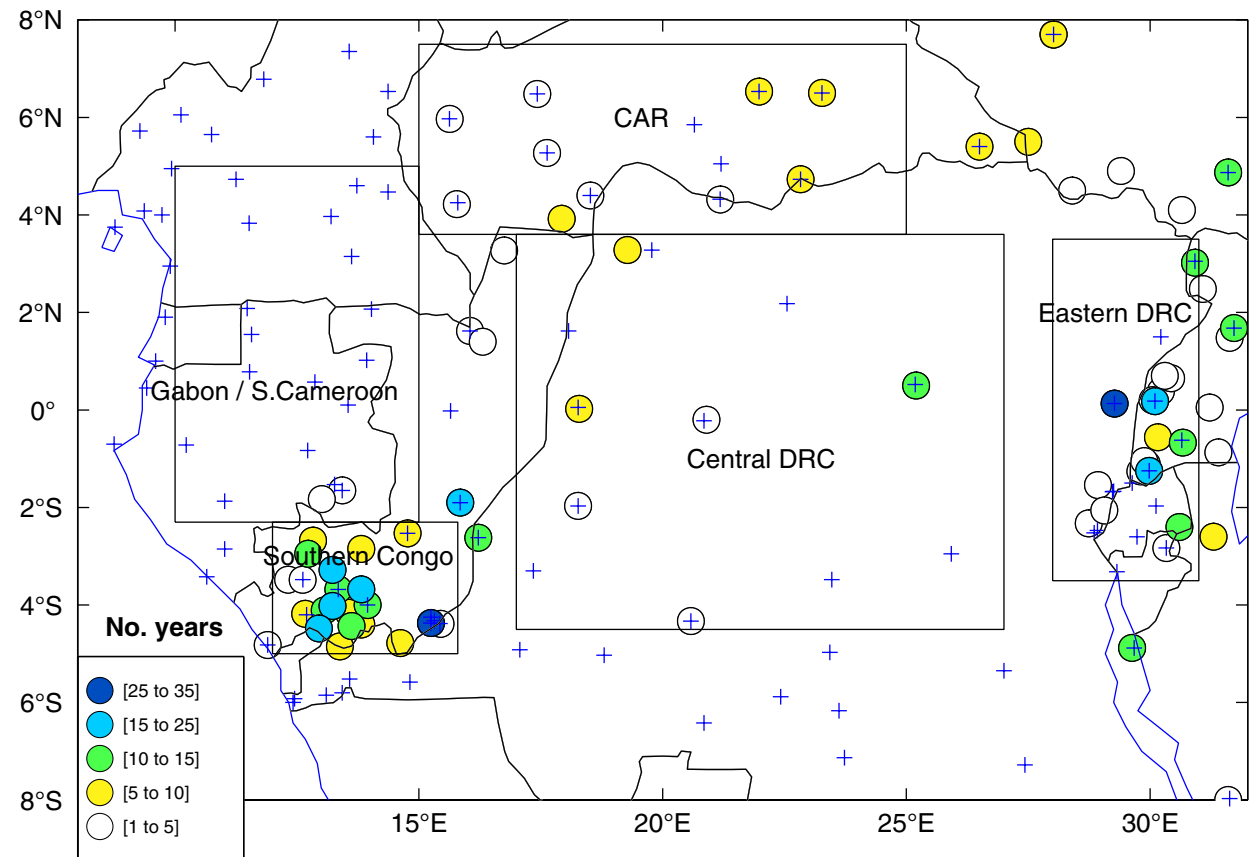

F I G U R E 2 Subregions defined for skill assessment (boxes) and number of years of independent daily data (colour circles). Crosses show stations from the GSOD network, and colour disks show the number of years of independent daily data available at each station. Boxed areas are referred to in the text, for skill assessments at daily (except for Gabon), monthly and interannual time-scales [Colour figure can be viewed at wileyonlinelibrary.com].

(mainly 2015-2017) using six fully independent automatic weather stations, to which we added Kinshasa-Binza, from the Mettelsat network but not included in global databases and having complete data over these recent years. The stations constituting this dataset are shown as white circles and labelled on Figure 1a. This sample of stations enables a detailed discussion of the skills and failures of the different estimates, in terms of rainfall occurrence and intensity, for different climatic environments (bimodal regimes of the lowland forest for Pokola and Mokabi, and eastern highlands for Idjwi, Matanda and Tshivanga, single-peak southern hemispherical regimes for Bakoumba and Kinshasa-Binza).

At the interannual time-scale, it is more difficult to extract a fully independent subset of data, since no list is available of the rain-gauge data incorporated in the merged satellite-rain-gauge products. However, maps of the station networks or number of stations per grid point are available for TARCAT (Maidment et al., 2014), CHIRPS (http:// chg.geog.ucsb.edu/data/chirps/, last accessed 25 March 2019) and GPCC (https://kunden.dwd.de/GPCC/Visualizer, last accessed 25 March 2019), the latter being used in the GPCP product, itself merged to obtain the PERSIANN estimates. In all these products, it was found that in southern Congo-Brazzaville only synoptic stations from the GTS network were incorporated. Over this region, the WaTFor database comprises a much larger number of stations (24), among which only seven are included in the GTS. Hence southern Congo-Brazzaville (see Figure 2 for location of the subregion) was selected for a detailed evaluation of interannual variations of monthly rainfall anomalies among the seven satellite products.

\section{RESULTS AND DISCUSSION}

\subsection{Mean annual rainfall}

Long-term mean annual rainfall amounts are first analysed, using all the available data from each of the seven rainfall products, and compared to both the WorldClim grid and the extended FAOCLIM stations (which were preferred to those of the WaTFor database which contains a smaller number of stations). Figure 3 shows the spatial patterns and Table $3 \mathrm{~A}$ the skill scores of the rainfall products against observed data. We verified that biases and skills found for each product are relatively robust and insensitive to the period considered, by carrying out a similar analysis on temporal subsets, e.g. 2011-2014 which is common to all seven products.

Central Africa shows high rainfall amounts near the Equator (1,700-2,200 mm/year, Figure 3a), decreasing both northward and southward, as well as east of the Western Rift Valley (about $30^{\circ} \mathrm{E}$ ). On the whole, all the products replicate this pattern well: spatial correlations with WorldClim range from 0.60 to 0.92 ( $N=140,845$ grid points), and from 0.56 to 0.97 with the extended FAOCLIM stations network $(N=641)$. The overall good matching between the correlations obtained against WorldClim and FAOCLIM demonstrates that uncertainties related to the interpolation of observed data in WorldClim do not interfere in the skill scores obtained in Table 3, 
(a)

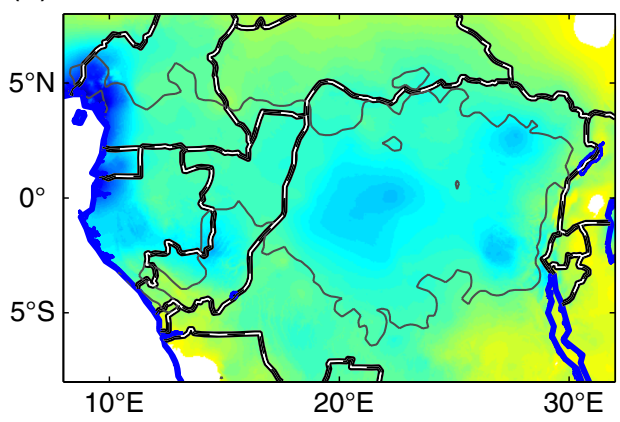

(c)

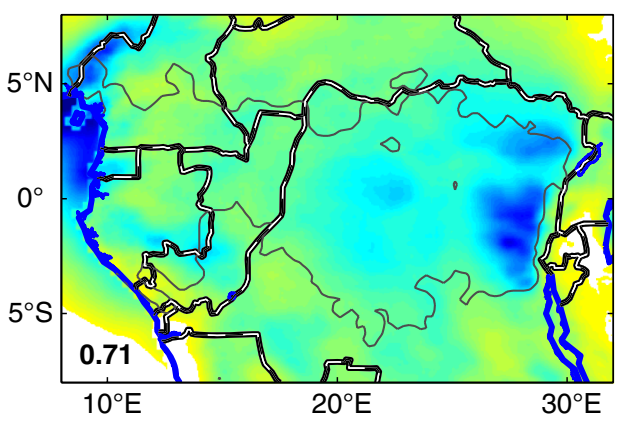

(e)

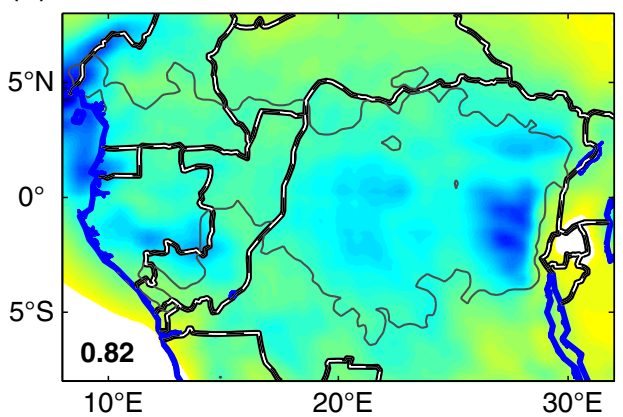

(g)

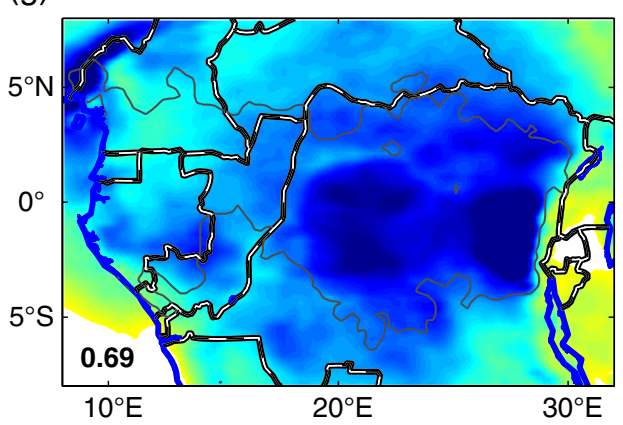

(b)

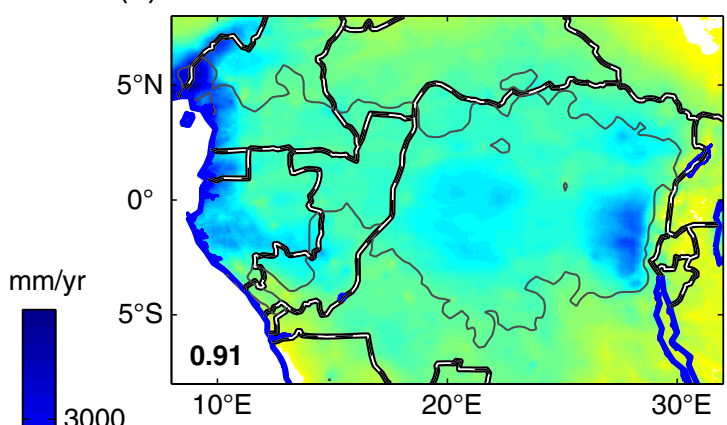

(d)

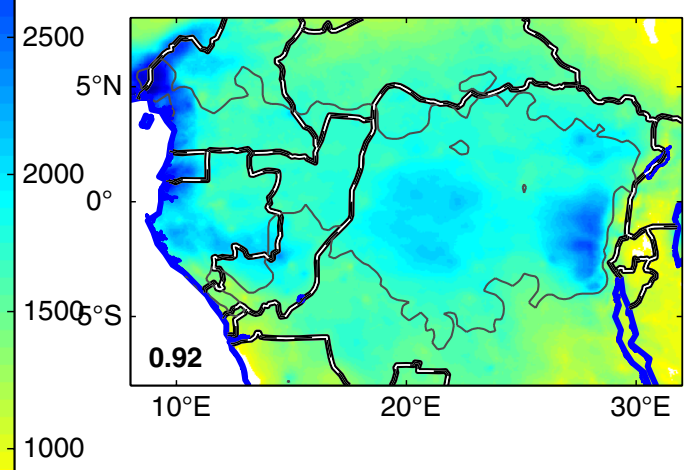

(f)

TMPA 1998-2014

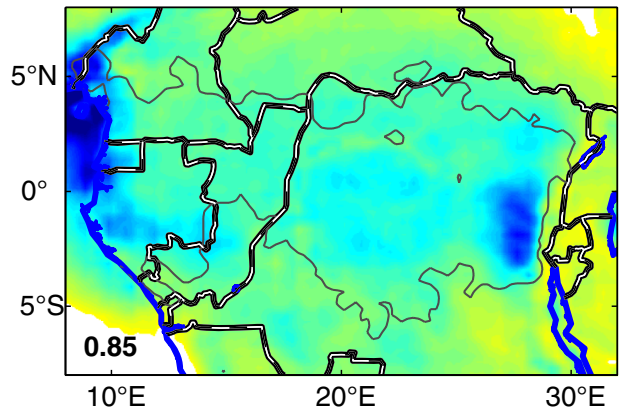

(h)

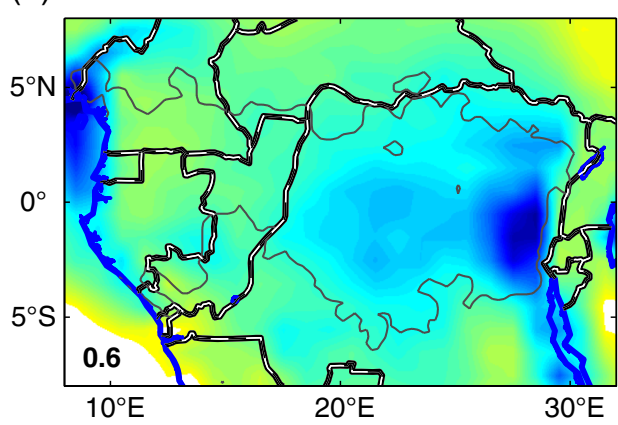

F I G U R E 3 (a) Mean annual rainfall from observations (WorldClim), and (b-h) seven satellite rainfall estimates products, based on all years available. Thin grey lines show the limits of the rainforest. The bottom-left values are the pattern correlations with WorldClim [Colour figure can be viewed at wileyonlinelibrary.com].

since correlations obtained with non-interpolated data (i.e. FAOCLIM stations) are relatively similar. However, while observed rainfall amounts tend to be relatively even all along the equatorial region $(\sim 1,700$ to $2,000 \mathrm{~mm} /$ year, with a slight increase in the west along the Atlantic coast in northern Gabon and southwestern Cameroon), some products fail to replicate this feature. A much higher rainfall in the east than in the west is often displayed, especially in ARC, CMORPH 
T A B L E 3 Skill scores of long-term mean annual rainfall (A) and mean monthly rainfall (B) from the 7 satellite rainfall estimates products against observed data (WorldClim and FAOCLIM)

\begin{tabular}{|c|c|c|c|c|c|c|c|}
\hline Dataset & CHIRPS & ARC & TARCAT & PERSIANN & TMPA & CMORPH & TAPEER \\
\hline Period & $1983-2017$ & 1983-2017 & $1983-2017$ & $1983-2017$ & 1998-2014 & 2003-2017 & 2011-2016 \\
\hline \multicolumn{8}{|l|}{ (A) Mean annual rainfall } \\
\hline Bias / WorldClim (mm/year) & $\underline{14}$ & -56 & 61 & 28 & -35 & 713 & 118 \\
\hline RMSE / WorldClim (mm/year) & $\underline{142}$ & 255 & 152 & 202 & 189 & 849 & 340 \\
\hline r / WorldClim & 0.91 & 0.73 & $\underline{0.92}$ & 0.82 & 0.85 & 0.69 & 0.60 \\
\hline r / FAOCLIM & $\underline{0.97}$ & 0.83 & 0.93 & 0.82 & 0.86 & 0.71 & 0.56 \\
\hline \multicolumn{8}{|l|}{ (B) Mean monthly rainfall } \\
\hline r / WorldClim & $\underline{0.97}$ & 0.91 & 0.94 & 0.95 & 0.94 & 0.87 & 0.88 \\
\hline r / FAOCLIM & $\underline{0.98}$ & 0.90 & 0.95 & 0.90 & 0.91 & 0.81 & 0.82 \\
\hline
\end{tabular}

Note: All correlations (r) are significant at $P>99.9 \%$. Number of observations for annual data: 140,845 (WorldClim grid-points) and 641 (FAOCLIM stations). Number of observations for monthly data: 1,690,140 (WorldClim grid-points-months) and 7,692 (FAOCLIM stations-months). The best skill score is shown in bold and is underlined, and the next two best ones are in bold. The lowest scores are in italics.

and TAPEER, as reflected in their relatively lower pattern correlations with observations compared to other products (Table 3A). The eastern maximum, near the Mitumba mountains $\left(27-28^{\circ} \mathrm{E}\right)$ is systematically overestimated and amounts to the west tend to be underestimated in ARC and TAPEER. These differences between the rainfall products have already been noted by Washington et al. (2013) and Awange et al. (2016). Some biases in the west could be related to a larger proportion of warm rains near the coast (resulting in an underestimation by the satellite products, especially ARC and PERSIANN, which rely on infrared images). In the rest of Central Africa warm rains are uncommon (Kodama et al., 2009). The overestimation of mean rainfall in eastern DRC by all products could be related to deep convection yielding lower than expected rainfall amounts as a possible result of inefficient rain processes (McCollum et al., 2000; Jackson et al., 2009), or to non-precipitating anvil clouds, as stratiform rains evolving from deep convective clouds account for an unusually low fraction of total rainfall in eastern Central Africa (Schumacher and Houze, 2003). In CMORPH, a systematic wet bias appears (Table $3 \mathrm{~A}$ and Figure 3) which is a well-known feature of this product for several parts of Africa (e.g. Habib et al., 2012; Awange et al., 2016) and is related to the fact that CMORPH is not merged with in situ rainfall observations. TARCAT and CHIRPS show the highest correlations with observations. CHIRPS has the smallest bias and RMSE (Table 3A). TMPA also exhibits very good skills, closely followed by PERSIANN. TAPEER displays the lowest skill in terms of pattern correlation, due to the initially coarse spatial resolution of this product, although the bias is moderate, and the north-south gradients are well reproduced. These contrasted skills between the satellite rainfall products are in line with Negrón Juárez et al. (2009) who found that discrepancies between the mean annual rainfall patterns of different global datasets were much larger over the Congo Basin than over the Amazon Basin. Note that the pattern correlations over the subset period 2011-2014 (not shown) are very similar to those obtained from the full sets. These correlations are only marginally lower for most datasets, reflecting the fact that an average computed over 4 years is slightly less robust, but the ranking of the seven products is unaffected.

\section{2 $\quad$ Mean monthly rainfall regimes}

In order to examine how well the products replicate the seasonal cycle of rainfall, spatially averaged rainfall regimes are computed over the five Central African subregions located on Figure 2, using all grid-points within a given subregion for both the satellite products and WorldClim. These subregions document the three main rainfall regimes found over Central Africa, as defined by Dezfuli (2017), as well as the more subtle east-west variations. A unimodal regime is found in the Central African Republic (CAR, Figure 4a), showing a single, long rainy season with maximum rainfall from August to October, and a dry season centred on December-February ( 3 months below $50 \mathrm{~mm}$ ). This seasonal pattern is well reproduced by all products. By contrast, southern Congo-Brazzaville (Figure 4c) exhibits high rainfall during the austral summer (above $100 \mathrm{~mm}$ from October to May), with peaks in November and April, and a very dry period from June to September. Most rainfall products replicate this pattern, although CMORPH overestimates rainfall amounts during the wet season and tends to produce higher rainfall in April than in November, in contrast to observation.

The three other subregions are closer to the Equator and display clear bimodal regimes with maxima in April and October, and minima around January and July. These are generally well reproduced by the satellite rainfall 
(a)

(a)

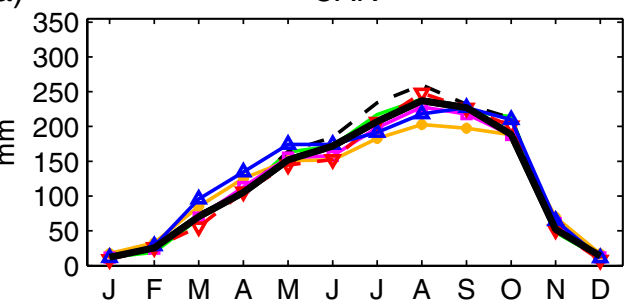

$$
\text { (c) }
$$

(c) 350

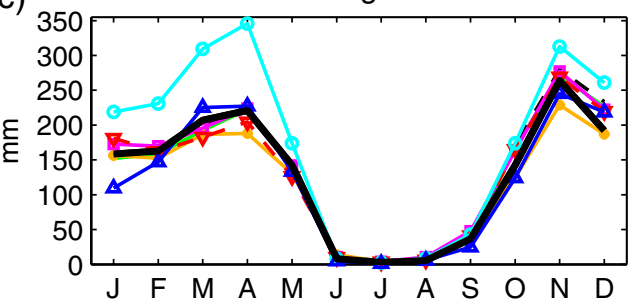

(e)

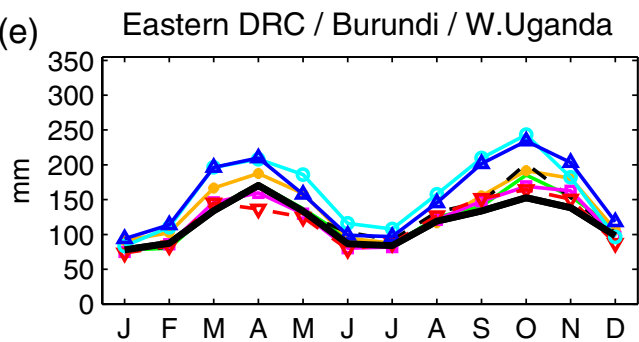

(b)

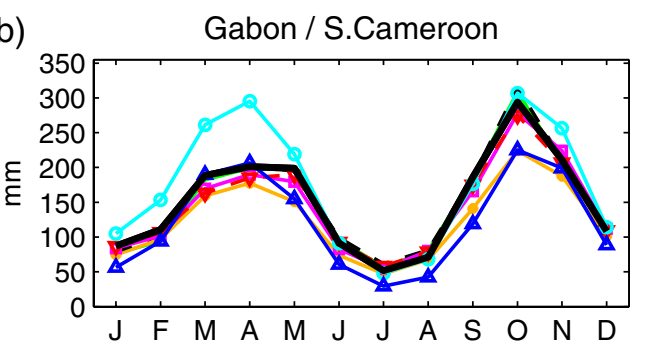

(d)

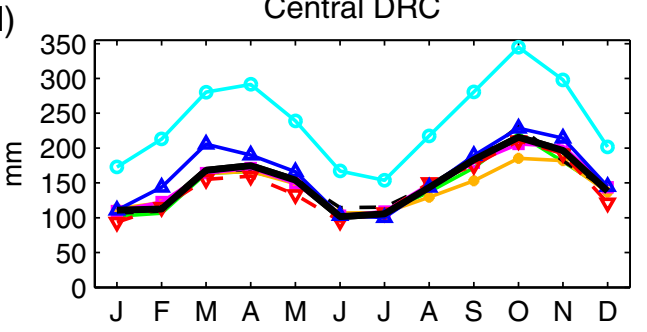

F I G U RE 4 (a-e) Mean monthly precipitation regimes averaged over the five subregions shown in Figure 2 [Colour figure can be viewed at wileyonlinelibrary.com].

products. In Gabon and southern Cameroon (Figure 4b), the boreal autumn season is wetter than the boreal spring season. CMORPH overestimates the boreal spring season, and TAPEER and ARC underestimate the boreal autumn rainy season. TAPEER and ARC slightly underestimate rainfall, especially in the second half of the year. The bimodal regimes of Central DRC (Figure 4d) are those where CMORPH overestimation is most pronounced ( +40 to $70 \%$ ), but the seasonal pattern is correct. Finally, the region around the Western Rift Valley (eastern DRC and western Uganda, Figure 4e) shows quite symmetrical rainy seasons, with slightly lower amounts than in central DRC. The bimodal pattern is well replicated by most products. CMORPH and TAPEER distinguish themselves by a systematic overestimation. Most other products display a small overestimation of the boreal autumn rainy season.

As a more general assessment, for Central Africa as a whole, correlations are computed between WorldClim and each product by considering mean monthly precipitation at all grid-points and months taken together (Table 3B). This enables a joint spatial and seasonal assessment of the climatology of the seven products. Very high correlations (from 0.87 to 0.97 ) are found for all products. This shows that on the whole the combined spatial and seasonal patterns of rainfall are well reproduced by the satellite rainfall estimates. CHIRPS leads, followed by PERSIANN, TARCAT and TMPA. Despite its low initial resolution, TAPEER has a correlation only marginally lower, close to CMORPH. This indicates a very good representation of the seasonal cycle in TAPEER, compensating for biases in the mean annual rainfall distribution. The bottom part of Table 3B shows that when substituting the extended FAOCLIM dataset to WorldClim (and now considering only those grid points where a FAOCLIM station is located), we obtain very similar correlations despite the smaller number of observations. This indicates that the above ranking of the skills of the satellite products is robust.

On the whole, these results show that monthly rainfall regimes are relatively well reproduced by most products.

\section{3 | Daily rainfall}

As a complementary and more severe test on rainfall products we now consider daily rainfall amounts, by comparing them to observations at all available stations together (WaTFor database, 154 stations). Skill scores are computed over the whole period of data availability ("full period", Figure 5) and over the sub-period 2011-2014 (common to all satellite products). This enables us to verify that differences in products skills are not an artefact of the time sampling. Like for 


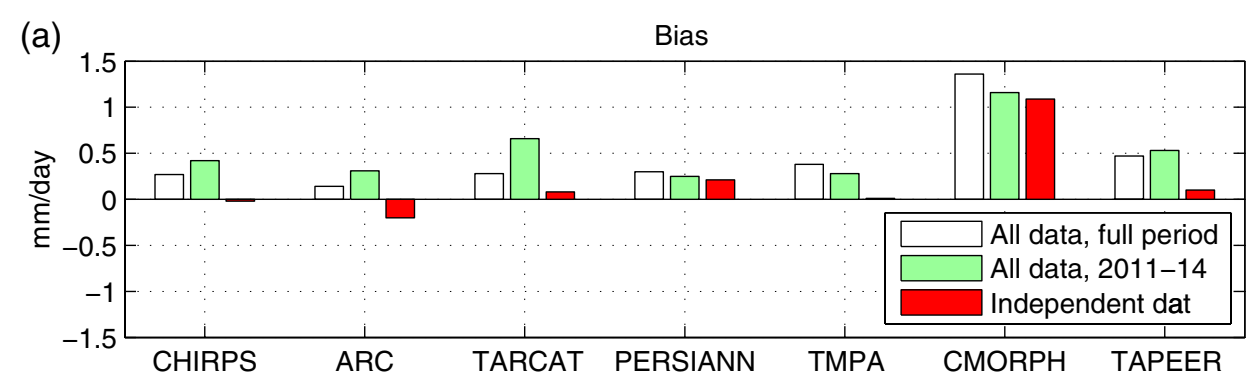

(b)

RMSE

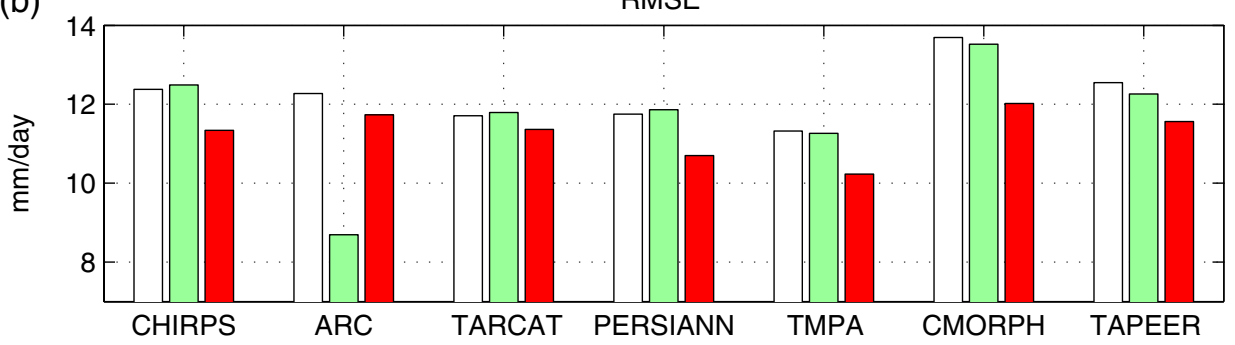

(c)

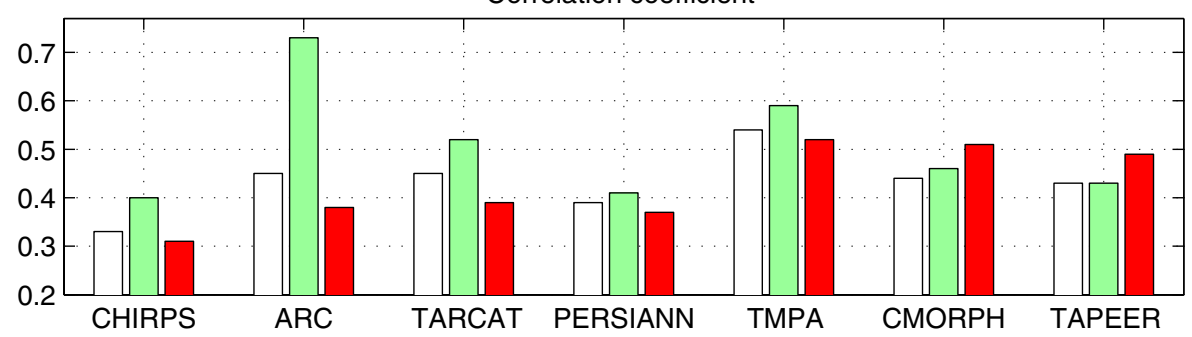

F I G U R E 5 Skill scores of daily satellite rainfall estimates compared to station observations, based on all the data available (full period, white leftside bars), on data for the sub-period 2011-2014 (common to all satellite products, green central bars), and on non-GSOD stations only (full period, red rightside bars, see text). (a) Bias, (b) RMSE, (c) correlation coefficient. Correlations are based on square-root transformed daily rainfall amounts [Colour figure can be viewed at wileyonlinelibrary.com].

the climatology, small differences are usually found between the full period and the shorter one, suggesting that results are temporally robust.

Biases confirm the findings based on annual rainfall. They are generally small and positive (between +0.3 and $+0.6 \mathrm{~mm} /$ day). CMORPH singularizes by having much larger positive biases $(+1.4 \mathrm{~mm} /$ day over the full period, i.e. about a third of the regional rainfall average). RMSE is a much more stringent test statistic, since it depends on the capacity to replicate the chronology of daily rainfall events and their intensity. Large errors are found for all products (RMSE generally between 11 and $13 \mathrm{~mm} /$ day). This partly results from the fact that gridded data are compared to point rainfall measurements, which show logically higher extremes. CMORPH has the highest RMSE, and TMPA has the lowest, but the difference barely exceeds $2 \mathrm{~mm}$. Skill scores do not strongly change over the short period (2011-2014) except for ARC (Figure 5). Reasons for this strange behaviour have not been clearly found in the documentation, but by scrutinizing the data it appears that in the recent years raw GTS (GSOD) station data are directly allocated to the corresponding grid point, while for earlier years these data are interpolated to a $0.1^{\circ}$ grid (Novella and Thiaw, 2013). This evidently raises skill scores over the recent sub-period and suggests that temporal inhomogeneities may exist in this product. Daily correlations also show that the performance of the products is relatively low, although all coefficients are highly significant $(P=99.9 \%)$ due to the huge number of records used in the comparison (ranging from over 58,000 for TAPEER to 521,000 for CHIRPS). The low correlations (except for ARC over the period 2011-2014, for the reason exposed above) are partly due to the scale mismatch between the gridded products and the station data. However, the ranking of the seven products, for the complete period, is instructive. TMPA displays the highest correlations, followed by CMORPH, TARCAT and ARC (with the above reservations). CHIRPS has slightly lower correlations. Similar assessments were carried out for timespans of between two and 30 days (not shown). As expected, correlations tend to increase as longer time-scales are considered. CHIRPS' performance, the poorest for the single-day evaluation, is found to rise faster than other products do with increasing time-scales (from a timespan of 14 days, it supersedes all other products except TMPA). On the contrary, TARCAT's performance only slowly improves with longer time-scales. 
T A B L E 4 Correlation coefficients between daily rainfall (square-root transformed) at independent rain-gauges and at the nearest grid point of the 7 satellite products, for 4 subregions of Central Africa

\begin{tabular}{|c|c|c|c|c|c|c|c|c|}
\hline & $N$ & CHIRPS & ARC & TARCAT & PERSIANN & TMPA & CMORPH & TAPEER \\
\hline CAR & $\begin{array}{l}15,777 \\
(621)\end{array}$ & 0.36 & 0.43 & 0.49 & 0.44 & $\underline{0.64}$ & 0.56 & $*$ \\
\hline $\begin{array}{l}\text { southern } \\
\text { CONGO-BRAZZAV }\end{array}$ & $\begin{array}{l}105,028 \\
(4018)\end{array}$ & 0.30 & 0.35 & 0.38 & 0.36 & $\underline{0.58}$ & 0.54 & 0.50 \\
\hline central DRC & $\begin{array}{l}16,270 \\
(14,865)\end{array}$ & 0.28 & 0.38 & $\underline{0.49}$ & 0.40 & $*$ & $*$ & $*$ \\
\hline eastern DRC & $\begin{array}{l}48,400 \\
(2049)\end{array}$ & 0.30 & 0.37 & 0.31 & 0.35 & 0.44 & 0.44 & $\underline{0.47}$ \\
\hline
\end{tabular}

Note: $N$ is the maximal (and minimal) number of daily records, which varies according to the number of records available both in the satellite estimates and at the stations. Stars denote that less than 600 daily records are available (typically for TAPEER which documents the period 2011-2016 only). The highest correlation for each subregion is shown in bold and is underlined, and the next one or two highest are in bold. The lowest correlation is in italics. All the correlations are significant at the $99 \%$ level.

As mentioned in section 3, the above comparison has limitations due to the fact that some products, for calibrating satellite estimates, use monthly, pentadal and sometimes daily data from various sources, mostly stations from the GTS, which are incorporated in the WaTFor database used as reference. Two additional analyses are therefore performed using independent data, which however do not cover the whole of Central Africa. The first one retains rainfall stations belonging to the national meteorological networks (mainly in CAR, Congo-Brazzaville and DRC), but whose data were not available in the GTS and therefore were not merged with the satellite estimates to obtain rainfall products. The second one considers automatic weather stations implemented in the framework of various projects, and which are not included in the national meteorological networks. These independent data enable a more detailed diagnostic of the satellite estimates skills.

On Figure 5, the same statistics as above have been computed for the subset of data independent from the GSOD database (red bars). Only little change is found for the mean bias. For RMSE, while ARC was showing good performance in the full database over the recent period, this product when confronted with fully independent data is now showing the largest error, as expected from above. RMSE slightly decreases for all other products, which is likely related to changes in the spatial sampling between the full and the independent datasets, but apart from ARC, their ranking is close to that obtained from the full dataset. CMORPH still has the highest error, and TMPA has the lowest one. TMPA also performs best in terms of correlation coefficients, well distancing ARC, whose correlation is now much lower when GSOD data are eliminated from the validating data. CMORPH and TAPEER also perform well and stand very close to TMPA, while the lower performance of CHIRPS is confirmed. A small reduction compared to the full dataset is found in all products which merge rain-gauge observations (except ARC) while they should have increased as the sole result of the different spatial sampling if we consider that CMOPRH and TAPEER, the only products which do not merge rain-gauge observations, have slightly higher correlations than in the full database.

Subregional assessments are presented in Table 4, for four of the five subregions formerly identified (Figure 2). Indeed, Gabon is not retained because it has too little independent data. Note also that for central DRC the lack of recent rain-gauge data prevents the evaluation of TMPA, CMORPH and TAPEER. All correlations are highly significant, but some differences are found between the products. A notable feature is that TMPA recurrently shows the highest correlation with observations (for the subregions where it can be evaluated). CHIRPS systematically has the lowest correlation. CMORPH generally displays quite high correlations, and TARCAT and PERSIANN are more uneven, performing well in central DRC and CAR, but less so in southern Congo-Brazzaville and eastern DRC.

Finally, we consider the set of automatic weather stations over the recent period (2015-2017, 2016-2017 or 2012-2017 depending on stations). Table 5 shows at each station the skill statistics of the seven satellite products. TMPA evaluation was done only at two stations (Bakoumba and Kinshasa) because the time series used did not extend beyond 2014 . However, for these two stations TMPA stands out by its high scores compared to other products (highest correlation, low false-alarm ratio and highest Heidke skill scores). It is noteworthy that the products, except TMPA, perform differently depending on the location and criteria. In northern Congo-Brazzaville (Pokola and Mokabi), TARCAT shows some of the best scores for both rainfall intensity (correlation) and rainfall occurrence (low FAR and high HSS). At stations located in eastern DRC, scores are generally lower for most rainfall products, likely due to the mountainous terrain and related high spatial rainfall variability where stations show 
T A B L E 5 Skill scores of daily rainfall at seven independent stations

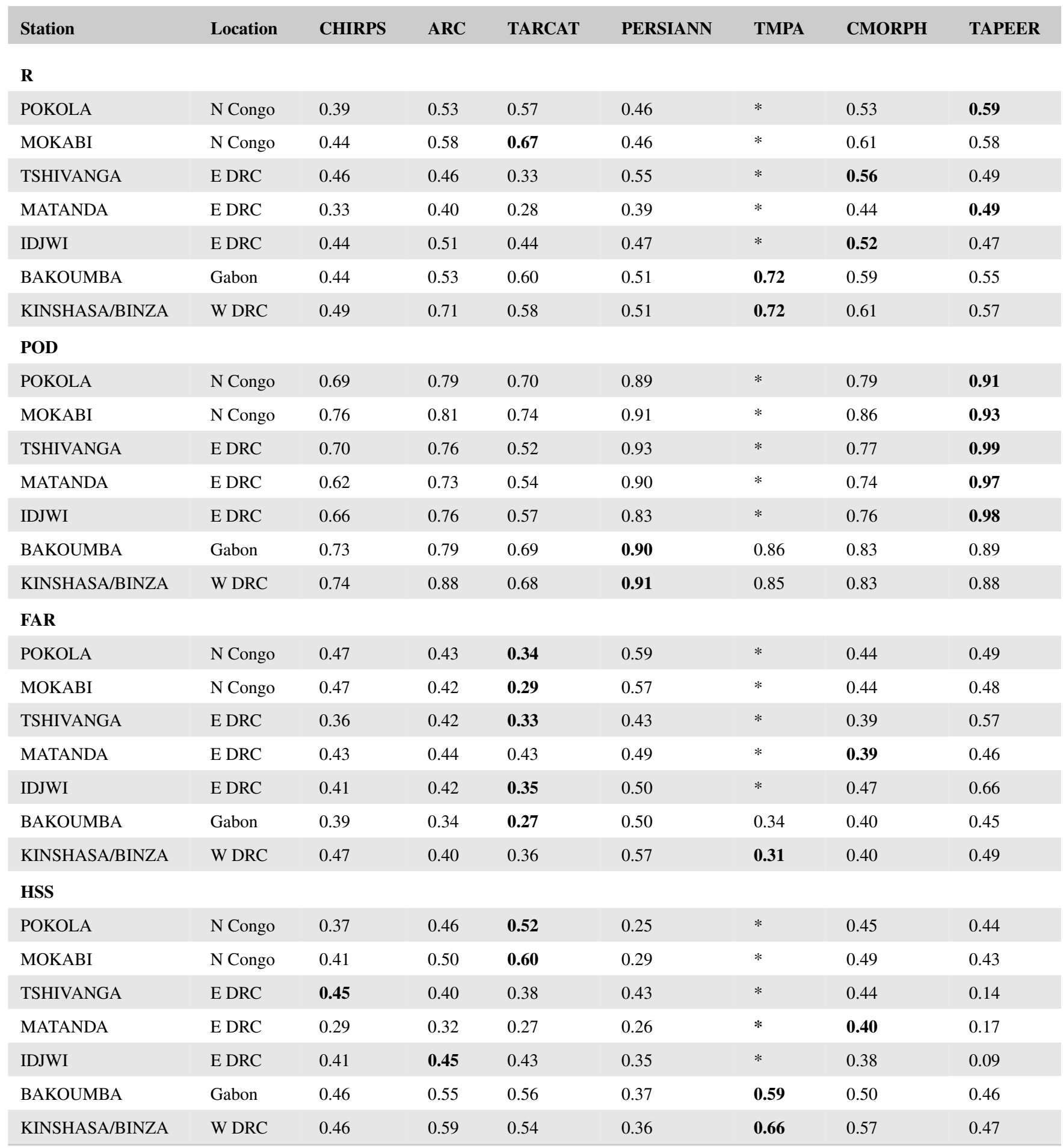

Note: All the correlations are significant at the 99\% level. Data are for 2012-2017 (Bakoumba, Kinshasa), 2015-2017 (Matanda) and 2016-2017 (Pokola, Mokabi, Tshivanga, Idjwi). Statistics are not computed if less than 200 observations are available. Bold figures show the product which displays the best skill.

Abbreviations: FAR, False-alarm ratio; HSS, Heidke skill score; POD, Probability of detection of wet days; R, Correlation coefficient (including wet and dry days computed on square-root transformed daily rainfall).

low spatial representativeness, introducing large uncertainties in the products' validation (Monsieurs et al., 2018). At these stations, scores are also relatively similar across the products, except for TAPEER which show poor HSS. This is related to its initial spatial resolution $\left(1^{\circ}\right.$ square), which does not adequately resolve the spatial variations in daily rainfall over this region. The high POD values for TAPEER are also related to the spatial smoothing associated with its low resolution, hence many actual dry days are incorrectly considered as wet (see the high FAR). CMORPH, despite showing large biases in mean monthly rainfall (section 4.1) displays relatively high daily correlations, including at rain-gauges 
of the eastern highland region. This is suggestive of the importance of microwave data in estimating rainfall amounts at short time-scales, especially over highland areas.

On the whole these results highlight significant spatial variations in the skills displayed by the different products, as a result of varying rainfall regimes and scales of rainfall systems. They also reveal that products showing biases in long-term mean rainfall (like CMORPH) can be efficient at reproducing the timing of daily rainfall.

\subsection{Interannual variability}

Because satellite rainfall estimates are often used to map trends and study teleconnections, it is important to assess how well interannual variability is reproduced by the selected rainfall estimates. To that end, we first use de-seasonalised monthly rainfall anomalies (zero mean and unit standard-deviation). Given the unequal number of observations available at each station, correlations are computed (for each station separately) by extracting 100 random samples of 30 observations and computing the median correlation (section 3). The five subregions are considered, and results summarized in box-plots. An overall correlation analysis is also carried out for the whole of Central Africa, using all rain-gauges together, provided that at least 60 monthly observations (5 years) per station are available. The southern Congo-Brazzaville subregion, where a large enough number of independent stations is available, is retained for further study.

Figure 6 shows for each product the correlations with observed rainfall anomalies. Correlations are spatially quite variable, therefore a summary by subregion is provided in Figure 7. Central DRC tends to exhibit the lowest skills for all products (the lack of enough rain-gauge data since the late 1990s prevents qualifying CMORPH, TAPEER and TMPA skill over this subregion). Only CHIRPS (0.46) and PERSIANN (0.36) have median correlations significant at $P>98 \%$. ARC and TARCAT show almost no skill. By contrast, Gabon-southern Cameroon shows high correlations, with CHIRPS leading (median: 0.72, and very little dispersion), followed by PERSIANN, ARC and TARCAT, the latter two just above the $98 \%$ significance level for their median correlation (other products could not be tested). Over eastern DRC and nearby Uganda and Burundi, most products are relatively skilful (Figures 6 and 7), except ARC and moreover TARCAT. This region is where the difference between stations (i.e. the spatial variability of correlation levels) tends to be the smallest, although correlations are not exceptionally high (medians between 0.31 and 0.61 ). Over southern Congo-Brazzaville, correlations do not strongly differ between the seven products (with TMPA leading), but there is a very wide range between stations, which will be discussed below. Similar spatial variations apply to the CAR subregion.
On the whole, this regional analysis of skill at interannual time-scale indicates that TMPA (based on the available information) is the best rainfall product. It is followed by CHIRPS, which over the longer period 1983-2017 has the best skills, though it shows over most subregions large differences between stations. ARC and TARCAT perform poorly.

The overall correlations between monthly rainfall anomalies over Central Africa as a whole (using all stations and all years) are all highly significant $(P=99.9 \%)$, but quite moderate, and confirm the above results. CHIRPS has the highest coefficient (0.56) closely followed by TMPA (0.55). CMORPH and PERSIANN also show relatively high correlations (0.48). Despite the lower initial spatial resolution of TAPEER, the correlation remains fair (0.45). ARC is slightly less skilful (0.41), and TARCAT closes the list $(r=0.31)$. This ranking is very different from that obtained at daily time-scale, possibly related to the difference in the products' gauge calibration procedure at varying spatio-temporal aggregation levels.

Because at the scale of Central Africa it is difficult to distinguish the stations which were used to calibrate some of the satellite products from independent stations, we focus on southern Congo-Brazzaville (including nearby DRC stations), a subregion where data availability is fair and independent stations are available. Only three rainfall products, CHIRPS, TARCAT and PERSIANN, were considered, covering the period 1983-2017. The four other products were excluded because they cover a shorter period over which the number of available, non-synoptic rain-gauges is too small (and for ARC, because of the temporal heterogeneity found in the daily data). A set of 24 stations mainly obtained from Météorologie Nationale du Congo in Brazzaville is used for validation (Figure 8). Among these stations, seven are synoptic stations included in the GTS network (named on Figure 8), and to the best of our knowledge, the rest of the stations are not used in the construction of the satellite rainfall estimates. Most stations have 15 years or more of data, and a minimum requirement of at least 5 years of monthly observations was set. On the whole, with the exception of Makabana, synoptic stations tend to obtain higher correlations than other stations (Figure 8), a reflection of the fact that some data from these stations (although incomplete) are used in the merging process for the three products under scrutiny. CHIRPS shows slightly higher correlations than PERSIANN for GTS stations, with Brazzaville and Kinshasa having the highest values, at 0.71 and 0.64 , respectively. This was expected given that these two stations have the largest number of GTS records. For the independent stations, PERSIANN tends to get slightly higher median correlations than CHIRPS, but like for CHIRPS, the range is wide, from 0.55 at Madingou, a station southwest of Mouyondzi, to less than 0.1 at some nearby rain-gauges. TARCAT has the lowest scores but, with some exceptions, its scores for GTS stations are about the 

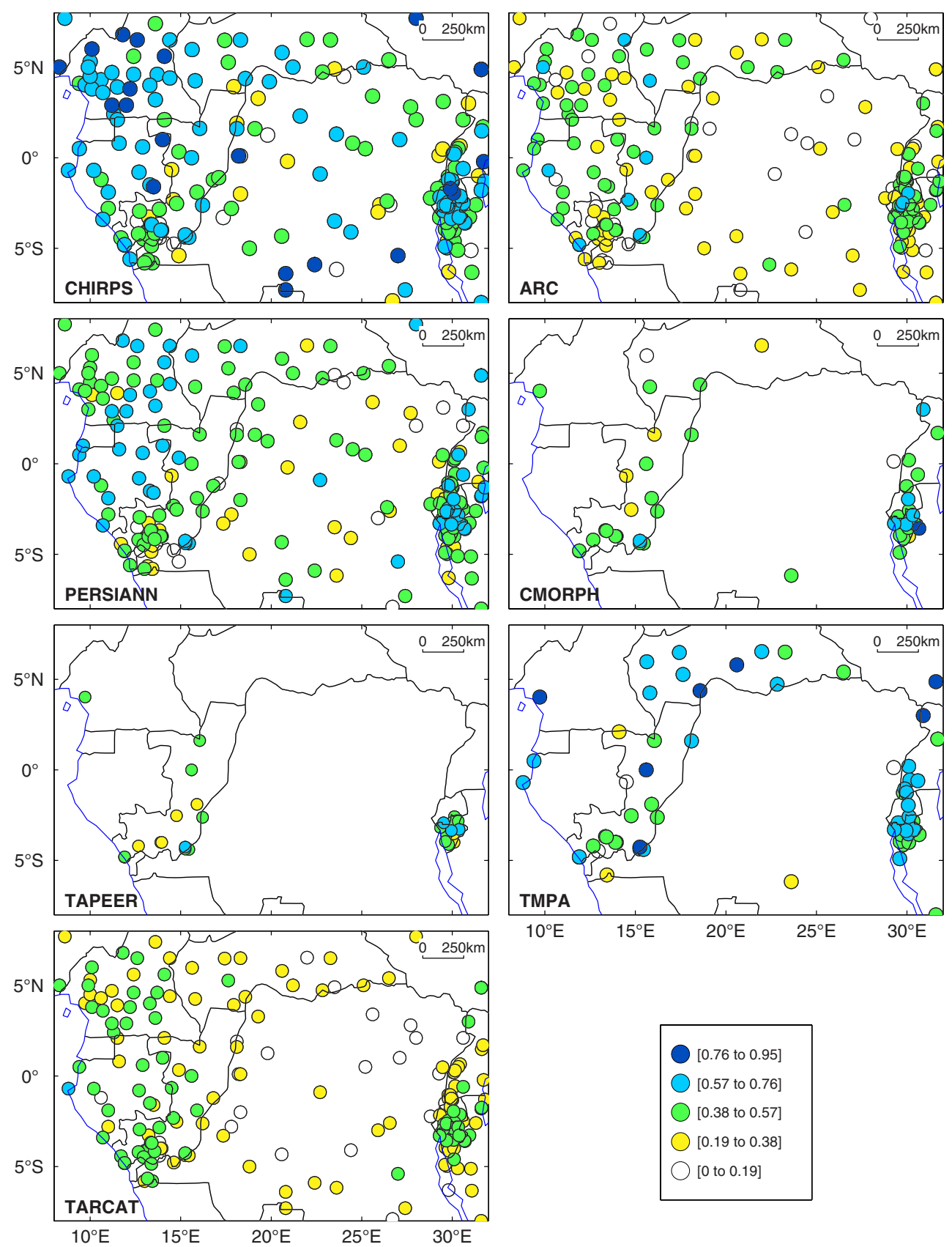

F I G U R E 6 Correlation between interannual monthly rainfall anomalies at rain-gauges and satellite rainfall estimates (all years available between 1983 and 2017). Values correspond to the median of 100 correlations computed from an ensemble of 100 samples of 30 monthly observations randomly selected from the records available at each station. A minimum number of 5 years of data ( 60 months) was required for a station to be used. A few negative correlations are set to zero. Correlations above 0.38 are statistically significant at the $98 \%$ confidence level (one-tailed test) [Colour figure can be viewed at wileyonlinelibrary.com].

same as those obtained for the independent stations, which can be explained by the fact that GTS data serve only in the calibration over large regions and are not incorporated per se in the product.

\section{5 | Dry season length}

As a final analysis, a tentative assessment is carried out which focuses on the length of the dry season. Although this is an important climate variable for rainforest environments, it is rarely considered when evaluating the skill of rainfall products. A preliminary test is carried out here for the Kinshasa-Binza station (DRC). This station, located in the southern Congo subregion, has a unimodal rainfall regime with a dry season (often locally and appropriately called "non-rainy season") in boreal summer (June-September). Kinshasa-Binza offers a long uninterrupted daily time-series over the period 1983-2017 which enables the computation 

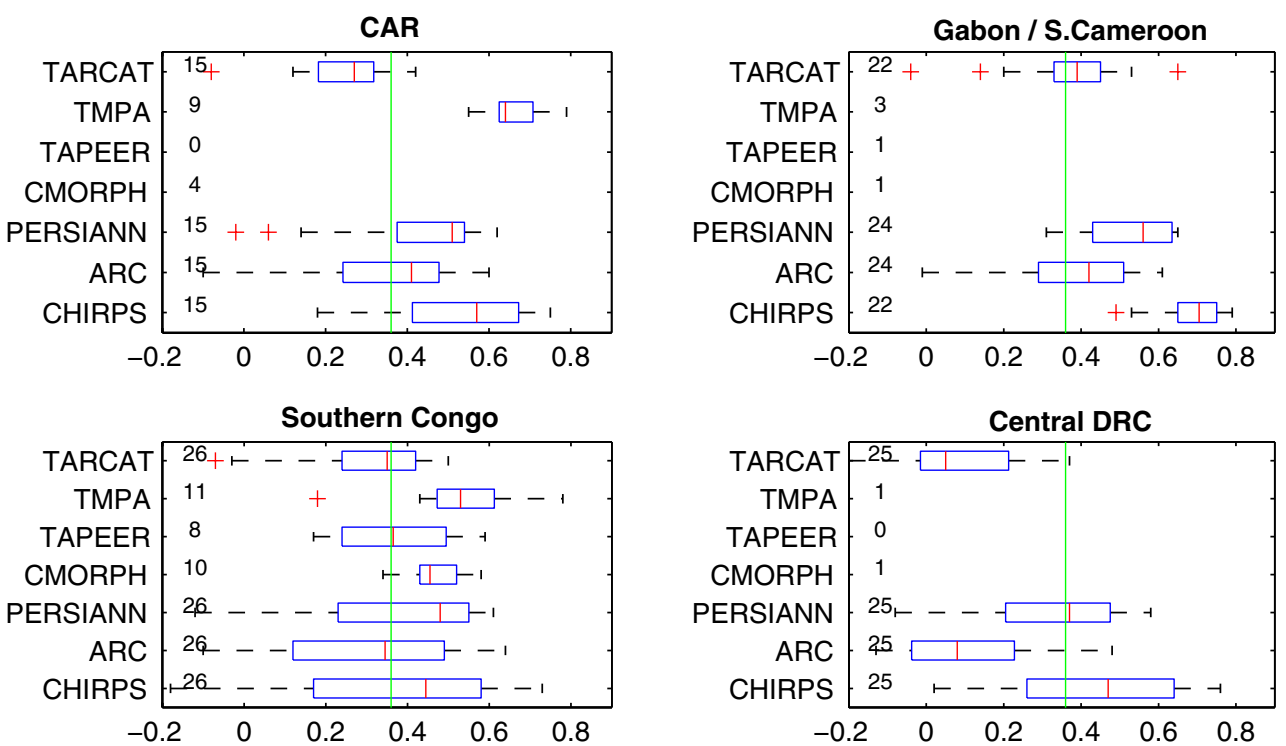

Eastern DRC / Burundi / W.Uganda

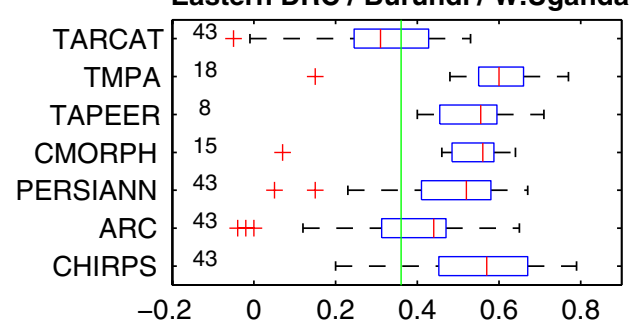

F I G U R E 7 Box-plots of interannual correlations between monthly rain-gauges and satellite rainfall anomalies, summarized over 5 selected subregions. Correlations are computed as in Figure 6. The value to the left of each box-plot shows the number of stations available (no box-plot is drawn when less than 8). This number also depends on the period of each satellite product. Green vertical lines show the $98 \%$ significance level [Colour figure can be viewed at wileyonlinelibrary.com].

of the dry season onset and cessation dates, thus the dry season length.

These dates were obtained by adapting the method used by Liebmann and Marengo (2001), Camberlin and Diop (2003) and Dunning et al. (2016) to determine wet season onset and cessation dates. Reference should be made to these publications for a full description of the method. To summarize, it consists in computing accumulated daily rainfall anomalies, for each year separately. Anomalies are differences between actual daily rainfall and the long-term daily mean. However, in the present study, after a careful testing, a coefficient of 0.7 was applied to this long-term daily mean value, in order to account for the overall wetness of the local climate. The maximum value of the accumulated anomalies during the period of time following the average peak of the rainy season denotes the beginning of the dry season, and the minimum value during the period of time preceding the average peak of the next rainy season denotes the end of the dry season. This method is more robust than simply considering the length of consecutive dry days, since in equatorial regions occasional showers often occur during the dry season yet they do not imply that the rainy season has started. Then, the dry season length is computed as the difference between the cessation date and the onset date, plus 1 day. The time series obtained from the satellite estimates (Figure 9) are dotted with several missing years, since even a few missing days prevent us from computing the onset and cessation dates. Table 6 provides the dry season mean duration for each estimate and its correlation with observations.

The observed duration of the dry season at Kinshasa ranges between 116 and 183 days, with an average of 151 days (Table 6 and Figure 9). This is slightly more than the duration found on the map published by Bultot (1971), about 120 days, as a probable result of the different method used, but very close to the average duration for nearby Brazzaville (about 160 days, based on "potentially useful rainy season": Samba et al., 1999). Almost all products have their mean dry season duration within 6 days of the observed mean duration. The interannual variability (standard deviation in Table 6) is generally slightly lower than that observed. TARCAT singularizes by a dry season which is bit too short, mainly because the dry season cessation comes on average 11 days too early. Correlation coefficients between observations and satellite products are all significant at $P>90 \%$ except for ARC and TARCAT. CHIRPS, PERSIANN and TMPA exhibit the largest and most significant correlation values. However, 
(a)

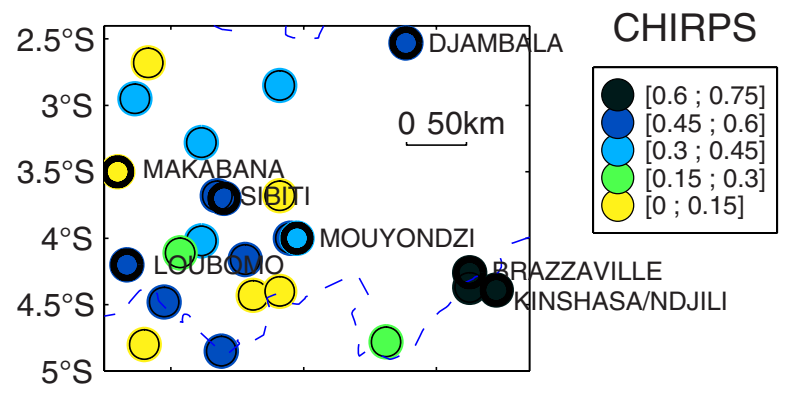

(b)

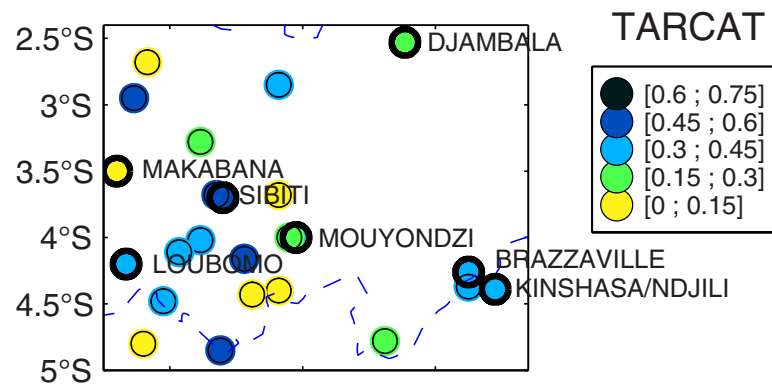

(c)

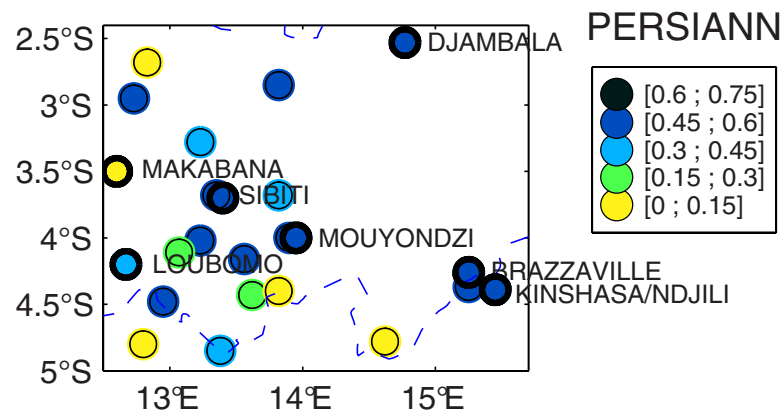

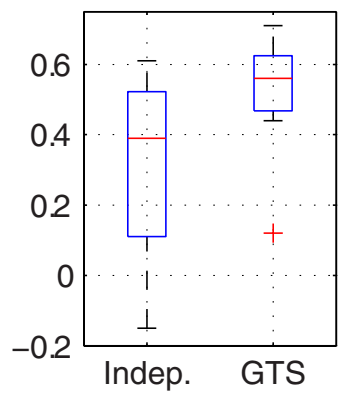
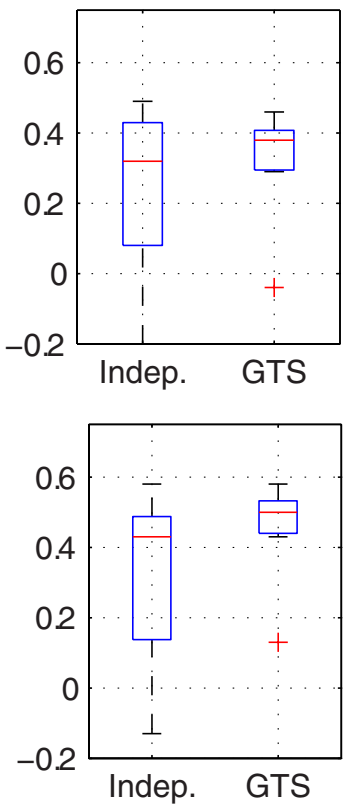

F I G U R E 8 (a-c) Local correlations between interannual variations of monthly observed rainfall anomalies and satellite rainfall estimates over the period 1983-2017, for the southern Congo-Brazzaville subregion. Synoptic stations included in the GTS network are named. Right panels: Box-plots of the correlation coefficients, shown separately for GTS stations and fully independent stations

Figure 9 also shows that there are only a few years (except for instance in 2015 and 2016) where all the products capture the right duration. Despite the very short length of records, TAPEER displays promising skills.

We compared these results to those obtained using alternative definitions of the dry season onset and cessation (Bombardi et al., 2019). The bias in TARCAT (too short dry season) is recurrently found whatever the methodology used to define the dry season. Using an agronomic definition of the dry season, it is confirmed that TMPA duration exhibits the best correlation with observed duration. However, the performance of other products varies much more (not shown).

This preliminary analysis of the dry season length reveals that this variable is not easily reproduced by satellite estimates, since it combines interannual variability of seasonal rainfall and the chronology of individual rainfall events. Yet, many estimates demonstrate usable skill, although a comparison with a larger number of stations would be necessary in order to rank the products according to their performance.

\section{CONCLUSION}

The performance of seven satellite rainfall estimates over Central Africa was evaluated by comparing them to rain-gauge observations, using an ad hoc dataset comprising partly not publicly available daily and monthly data as well as long-term averages, both gridded and at station scale. Different metrics and time-scales were considered, from mean annual rainfall fields to seasonal regimes, daily rainfall amounts, interannual variations of monthly anomalies. The skill of the products for dry season length monitoring was also tested. Noticeable differences are found in the performance of the seven products, related to their respective rainfall estimation algorithm which in some cases includes rain-gauge observations for data merging or calibration, yet at varying time-scales. The analysis was carried out over the period 1983-2017, or shorter periods depending on the satellite product availability. Care was exerted in verifying that results were not sensitive to the period investigated and to the number of observations. When possible, a differentiation 


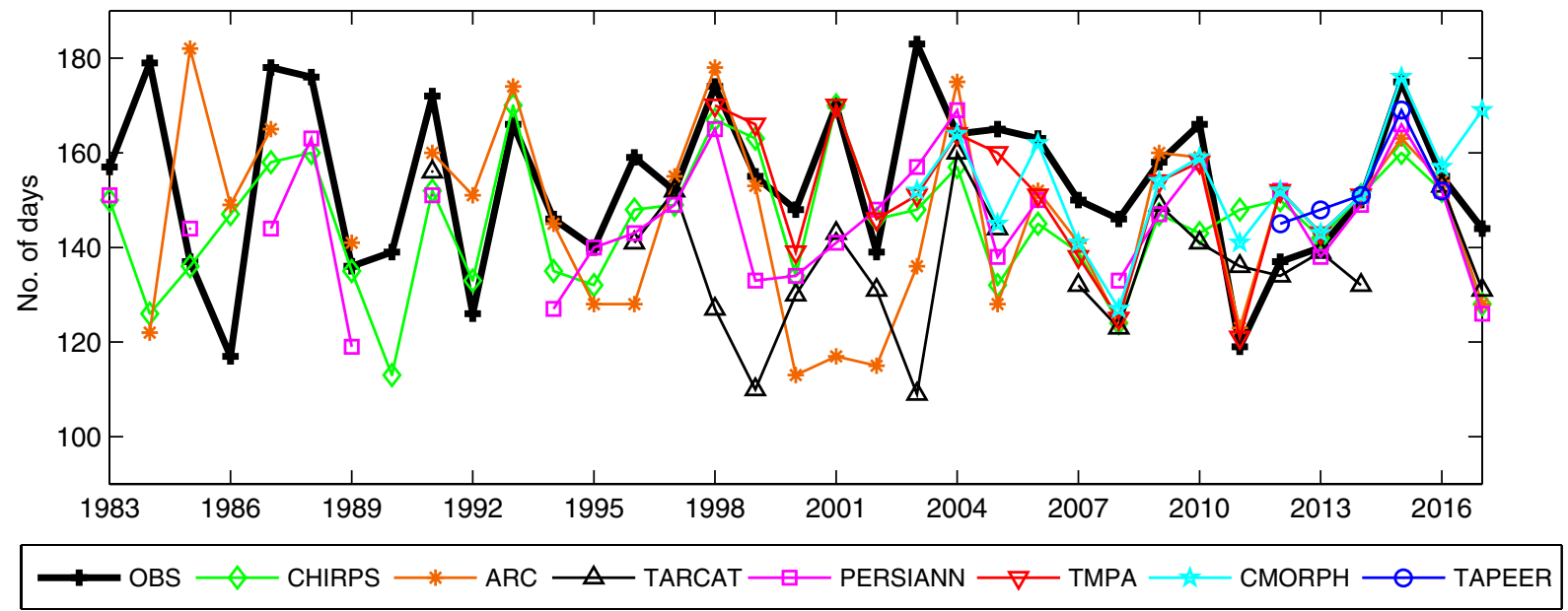

F I G U R E 9 Interannual variations of the length of the main dry season (in days) at Kinshasa-Binza (DRC) from 1983 to 2017, based on rain-gauge observations (OBS) and satellite products. The dry season duration is obtained as the time period between the maximum and the minimum accumulated daily rainfall anomalies (see text) [Colour figure can be viewed at wileyonlinelibrary.com].

T A B L E 6 Statistics on dry season length at Kinshasa-Binza (DRC)

\begin{tabular}{|l|lllll|}
\hline & $\begin{array}{l}\text { Mean } \\
\text { length } \\
\text { (days) }\end{array}$ & $\begin{array}{l}\text { Standard } \\
\text { deviation } \\
\text { (days) }\end{array}$ & $\begin{array}{l}\text { Number } \\
\text { of years }\end{array}$ & $\begin{array}{l}\text { Correlation } \\
\text { with observation }\end{array}$ & $P$-value \\
\hline OBSERVATION & 151 & 18.6 & 35 & & \\
\hline CHIRPS & 145 & 13.4 & 35 & 0.44 & .008 \\
\hline ARC & 146 & 18.4 & 31 & 0.21 & .240 \\
\hline TARCAT & 137 & 13.5 & 21 & 0.05 & .819 \\
\hline PERSIANN & 146 & 12.4 & 28 & 0.60 & .001 \\
\hline TMPA & 151 & 14.2 & 17 & 0.72 & .001 \\
\hline CMORPH & 153 & 12.5 & 15 & 0.47 & .078 \\
\hline TAPEER & 151 & 11.0 & 5 & $(0.97)$ & $(.007)$ \\
\hline
\end{tabular}

was made between independent stations and those used in the merging process with the satellite data.

The main findings are as follows:

1. There is an overall good reproduction of the mean rainfall regimes and the spatial patterns of mean annual rainfall, though some discrepancies exist in the longitudinal distribution of rainfall along the Equator from Gabon to the eastern DRC: several products show much higher precipitation in the east than in the west, whereas higher amounts are found in the observations along the Atlantic Ocean coastline.

2. Products like CMORPH which do not incorporate rain-gauge observations show, as expected, the largest systematic biases, but this does not mean that they perform badly in terms of rainfall variability.

3. Though not the best performing product, TAPEER has reasonable skills, despite its lower spatial resolution. A longer period of record will confirm its potentialities.
4. At the daily time-scale, TMPA is the best product (quite consistently over the different parts of Central Africa) and CMORPH ranks second (except for the systematic biases), although over central DRC among the four available products for the period of data availability, TARCAT performs best. More generally TARCAT is amongst the best products in terms of rain event detection. As emphasized by Dinku et al. (2018) for East Africa, this may be explained by the fact that TARCAT uses local calibration to select cold-cloud duration thresholds.

5. At the interannual time-scale, CHIRPS and TMPA perform best, although when compared against fully independent stations (southern Congo-Brazzaville) PERSIANN has comparable skills. TARCAT has the lowest correlations with observations. Interannual variations in all products should be taken with caution, especially given that rainfall exhibits a much weaker spatial coherence than in other parts of Africa (Camberlin et al., 2011). 
6. A tentative study of dry season length temporal variability indicated that it is a difficult variable to reproduce, and correlations with observations are moderate only. Unfortunately, there is a lack of daily records for a thorough validation, and algorithms based on daily data are demanding (no gaps allowed).

Discrepancies between the satellite rainfall products and their different subregional skills arise from various origins. Besides the fact that some satellite products are merged with in situ data, use them for calibration only or do not use ground observations at all, part of the discrepancies are related to the characteristics and physics of precipitation and the nature of the satellite data (infrared, radar, passive microwave). At a daily time-scale, the incorporation of microwave data markedly enhances skills, especially over highland areas where the relationship between cold clouds and rainfall amounts deteriorates, making the input from microwave data more decisive. In the lowlands however, the spatially varying calibration adopted in TARCAT enhances rain detection. At an interannual time-scale, whatever the product, skills tend to be higher in Western Central Africa, a subregion which shows larger and spatially more consistent interannual rainfall variability, as a result of slightly stronger teleconnections with Atlantic Ocean sea-surface temperature (Nicholson and Dezfuli, 2013).

It is difficult from these results to infer any definitive conclusion on the capacity of the various products to properly document long-term trends over the region. The virtual lack of rain-gauge observations in most of DRC since the early 1990s, added to the high spatial variability in interannual rainfall anomalies over Central Africa, should make users of merged satellite-rain-gauge products over this region very careful. In particular, inconsistencies found in the ARC product should refrain from using it to document trends. Further improvements of satellite rainfall estimates could gain from the use of remote-sensed soil moisture data, as demonstrated over West Africa (Pellarin et al., 2013).

\section{ACKNOWLEDGEMENTS}

The authors would like to thank Sylvie Gourlet-Fleury and Eric Forni (CIRAD Montpellier) for the provision of the Pokola and Mokabi rainfall data, and Marie Charpentier (CEFE) for the Bakoumba data. Bertil Ndlend (University of Douala/Université Bourgogne Franche-Comté), Sylvain Ndjendolé (Université de Bangui), Jean-Damien Maloba-Makanga (Université Omar-Bongo, Libreville) and Pierre Ozer (Université de Liège) are also thanked for their help in data collection. Marielle Gosset (GET Toulouse) assisted by making available the TAPEER dataset. Elise Monsieurs received financial support from BELSPO for the RESIST (SR/00/305) research project (http://resist. africamuseum.be/) and a F.R.S.-FNRS PhD scholarship. The DynAfFor project was supported by the French Fund for the Global Environment (FFEM, grant no. CZZ1636.01D). The WaTFor project was supported by the French Centre National d'Etudes Spatiales (CNES).

\section{OR CID}

Pierre Camberlin (10) https://orcid.org/0000-0003-4896-2332

\section{REFERENCES}

Adler, R.F., Gu, G. and Huffman, G.J. (2012) Estimating climatological bias errors for the Global Precipitation Climatology Project (GPCP). Journal of Applied Meteorology and Climatology, 51(1), 84-99.

Ashouri, H., Hsu, K.L., Sorooshian, S., Braithwaite, D.K., Knapp, K.R., Cecil, L.D., Nelson, B.R. and Prat, O.P. (2015) PERSIANN-CDR: daily precipitation climate data record from multisatellite observations for hydrological and climate studies. Bulletin of the American Meteorological Society, 96(1), 69-83.

Awange, J.L., Ferreira, V.G., Forootan, E., Khandu, Andam-Akorful, S.A., Agutu, N.O. and He, X.F. (2016) Uncertainties in remotely sensed precipitation data over Africa. International Journal of Climatology, 36, 303-323. https://doi.org/10.1002/joc.4346.

Beighley, R.E., Ray, R.L., He, Y., Lee, H., Schaller, L., Andreadis, K.M., Durand, M., Alsdorf, D.E. and Shum, C.K. (2011) Comparing satellite derived precipitation datasets using the Hillslope River Routing (HRR) model in the Congo River basin. Hydrological Processes, 25, 3216-3229.

Bigot, S., Camberlin, P., Moron, V. and Richard, Y. (1997) Structures spatiales de la variabilité des précipitations en Afrique: une transition climatique à la fin des années 1960? Comptes Rendus de l'Académie des Sciences, 324, 181-188.

Boisier, J.P., Ciais, P., Ducharne, A. and Guimberteau, M. (2015) Projected strengthening of Amazonian dry season by constrained climate model simulations. Nature Climate Change, 5(7), 656-660.

Bombardi, R.J., Moron, V. and Goodnight, J.S. (2019) Detection, variability, and predictability of monsoon onset and withdrawal dates: a review. Climate Dynamics, in press.

Buarque, D.C., de Paiva, R.C.D., Clarke, R.T. and Mendes, C.A.B. (2011) A comparison of Amazon rainfall characteristics derived from TRMM, CMORPH and the Brazilian national raingauge network. Journal of Geophysical Research, 116, D19105. https://doi. org/10.1029/2011JD016060.

Bultot, F. (1971) Atlas climatique du bassin Congolais. Les composantes du bilan d'eau, Vol. 2. Brussels: Institut National pour l'Étude Agronomique du Congo, p. 25.

Camberlin, P., Castel, T., Richard, Y. and Williamson, D. (2011) Montagnes d'Afrique Tropicale: marqueurs de la variabilité climatique ou isolats climatiques? Proceedings, 24th Conference of the Association Internationale de Climatologie, Climat montagnard et risques, 6-11 September 2011, Rovereto, Italy: AIC / Università di Ferrara, pp. 129-134. https://hal.archives-ouvertes.fr/hal-00625600.

Camberlin, P. and Diop, M. (2003) Application of daily rainfall principal component analysis to the assessment of the rainy season characteristics in Senegal. Climate Research, 23(2), 159-169.

Camberlin, P., Janicot, S. and Poccard, I. (2001) Seasonality and atmospheric dynamics of the teleconnection between African rainfall and 
tropical ocean surface temperature: Atlantic vs. ENSO. International Journal of Climatology, 21, 973-1005.

Chambon, P., Jobard, I., Roca, R. and Viltard, N. (2013) An investigation of the error budget of tropical rainfall accumulation derived from merged passive microwave and infrared satellite measurements. Quarterly Journal of the Royal Meteorological Society, 139(673), 879-893.

Cohen Liechti, T., Matos, G.D.S.C., Pedro, J., Boillat, J.L. and Schleiss, A. (2012) Comparison and evaluation of satellite derived precipitation products for hydrological modeling of the Zambezi River basin. Hydrology and Earth System Sciences, 16, 489-500.

Dembélé, M. and Zwart, S.J. (2016) Evaluation and comparison of satellite-based rainfall products in Burkina Faso, West Africa. International Journal of Remote Sensing, 37(17), 3995-4014.

Dezfuli, A.K. (2017) Climate of Western and Central Equatorial Africa. Oxford Research Encyclopedia of Climate Science. Available at: http://climatescience.oxfordre.com [Accessed 23rd January 2019].

Diem, J.E., Hartter, J., Ryan, S.J. and Palace, M.W. (2014) Validation of satellite rainfall products for western Uganda. Journal of Hydrometeorology, 15, 2030-2038. https://doi.org/10.1175/JHM-D-13-0193. 1.

Diem, J.E., Konecky, B.L., Salerno, J. and Hartter, J. (2019) Is equatorial Africa getting wetter or drier? Insights from an evaluation of long-term, satellite-based rainfall estimates for western Uganda. International Journal of Climatology. https://doi.org/10.1002/joc. 6023.

Dinku, T., Funk, C., Peterson, P., Maidment, R., Tadesse, T., Gadain, H. and Ceccato, P. (2018) Validation of the CHIRPS satellite rainfall estimates over eastern Africa. Quarterly Journal of the Royal Meteorological Society, 144(S1), 292-312. https://doi.org/10.1002/ qj.3244.

Dunning, C.M., Black, E.C. and Allan, R.P. (2016) The onset and cessation of seasonal rainfall over Africa. Journal of Geophysical Research: Atmospheres, 121(19), 11405-11424.

Ebert, E.E. (2007) Methods for verifying satellite precipitation estimates. In: Levizzani, V. , Bauer, P. and Turk, F.J. (Eds.) Measuring Precipitation from Space: EURAINSAT and the Future. Dordrecht: Springer, pp. 345-356.

Engel, T., Fink, A.H., Knippertz, P., Pante, G. and Bliefernicht, J. (2017) Extreme precipitation in the west African cities of Dakar and Ouagadougou: atmospheric dynamics and implications for flood risk assessments. Journal of Hydrometeorology, 18(11), 2937-2957.

FAO. (2001) FAOCLIM 2.0 A World-Wide Agroclimatic Database. Rome: Food and Agriculture Organization of the United Nations. Available at: http://www.fao.org/nr/climpag/pub/en1102_en.asp [Accessed 25 April 2019].

Fick, S.E. and Hijmans, R.J. (2017) WorldClim 2: new 1-km spatial resolution climate surfaces for global land areas. International Journal of Climatology, 37(12), 4302-4315.

Fu, R., Yin, L., Li, W., Arias, P.A., Dickinson, R.E., Huang, L., Chakraborty, S., Fernandes, K., Liebmann, B., Fisher, R. and Myneni, R.B. (2013) Increased dry-season length over southern Amazonia in recent decades and its implication for future climate projection. Proceedings of the National Academy of Sciences, 110(45), 18110-18115.

Funk, C., Peterson, P., Landsfeld, M., Pedreros, D., Verdin, J., Shukla, S., Husak, G., Rowland, J., Harrison, L., Hoell, A. and Michaelsen, J. (2015) The climate hazards infrared precipitation with stations - a new environmental record for monitoring extremes. Scientific Data, 2,150066
Gosset, M., Alcoba, M., Roca, R., Cloché, S. and Urbani, G. (2018) Evaluation of TAPEER daily estimates and other GPM-era products against dense gauge networks in West Africa, analysing ground reference uncertainty. Quarterly Journal of the Royal Meteorological Society, 144(S1), 255-269. https://doi.org/10.1002/qj.3335.

Gosset, M., Viarre, J., Quantin, G. and Alcoba, M. (2013) Evaluation of several rainfall products used for hydrological applications over West Africa using two high-resolution gauge networks. Quarterly Journal of the Royal Meteorological Society, 139, 923-940.

Habib, E., ElSaadani, M. and Haile, A.T. (2012) Climatology-focused evaluation of CMORPH and TMPA satellite rainfall products over the Nile Basin. Journal of Applied Meteorology and Climatology, 51, 2105-2121.

Heaney, A., Little, E., Ng, S. and Shaman, J. (2016) Meteorological variability and infectious disease in Central Africa: a review of meteorological data quality. Annals of the New York Academy of Sciences, 1382(1), 31-43.

Hua, W., Zhou, L., Chen, H., Nicholson, S.E., Raghavendra, A. and Jiang, Y. (2016) Possible causes of the central equatorial African long-term drought. Environmental Research Letters, 11(12), 124002.

Huffman, G.J., Bolvin, D.T., Braithwaite, D., Hsu, K., Joyce, R., Xie, P. and Yoo, S.H. (2015) NASA global precipitation measurement (GPM) integrated multi-satellite retrievals for GPM (IMERG). Algorithm theoretical basis document, version 4, NASA, pp 30.

Huffman, G.J., Bolvin, D.T., Nelkin, E.J., Wolff, D.B., Adler, R.F., Gu, G., Hong, Y., Bowman, K.P. and Stocker, E.F. (2007) The TRMM multisatellite precipitation analysis (TMPA): quasi-global, multiyear, combined-sensor precipitation estimates at fine scales. Journal of Hydrometeorology, 8(1), 38-55.

Jackson, B., Nicholson, S.E. and Klotter, D. (2009) Mesoscale convective systems over western equatorial Africa and their relationship to large-scale circulation. Monthly Weather Review, 137(4), 1272-1294.

Joyce, R.J., Janowiak, J.E., Arkin, P.A. and Xie, P. (2004) CMORPH: a method that produces global precipitation estimates from passive microwave and infrared data at high spatial and temporal resolution. Journal of Hydrometeorology, 5(3), 487-503.

Kodama, Y.M., Katsumata, M., Mori, S., Satoh, S., Hirose, Y. and Ueda, H. (2009) Climatology of warm rain and associated latent heating derived from TRMM PR observations. Journal of Climate, 22(18), 4908-4929.

Kubota, T., Shige, S., Hashizume, H., Aonashi, K., Takahashi, N., Seto, S., Hirose, M., Takayabu, Y.N., Ushio, T., Nakagawa, K., Iwanami, K., Kachi, M. and Okamoto, K. (2007) Global precipitation map using satellite-borne microwave radiometers by the GSMaP project: production and validation. IEEE Transactions on Geoscience and Remote Sensing, 45(7), 2259-2275.

Lewis, S.L., Lopez-Gonzalez, G., Sonké, B., Affum-Baffoe, K., Baker, T.R., Ojo, L.O., Phillips, O.L., Reitsma, J.M., White, L., Comiskey, J.A. and Ewango, C.E. (2009) Increasing carbon storage in intact African tropical forests. Nature, 457(7232), 1003-1006.

Liebmann, B. and Marengo, J. (2001) Interannual variability of the rainy season and rainfall in the Brazilian Amazon Basin. Journal of Climate, 14(22), 4308-4318.

Lott, N., Vose, R., Del Greco, S.A., Ross, T., Worley, S. and Comeaux, J. (2008). The integrated surface database: partnerships and progress, in Proceedings of 88th AMS Annual Meeting, 20-24 January 2008, New Orleans, LA. American Meteorological Society, pp. 1-3.

Love, T.B., Kumar, V., Xie, P.P. and Thiaw, W. (2004). A 20-year daily Africa precipitation climatology using satellite and gauge data. 
Preprints, 14th Conference on Applied Climatology, Seattle, WA: American Meteorological Society, pp. 5.4.

Maidment, R.I., Allan, R.P. and Black, E. (2015) Recent observed and simulated changes in precipitation over Africa. Geophysical Research Letters, 42(19), 8155-8164.

Maidment, R.I., Grimes, D., Allan, R.P., Tarnavsky, E., Stringer, M., Hewison, T., Roebeling, R. and Black, E. (2014) The 30 year TAMSAT African Rainfall Climatology And Time series (TARCAT) data set. Journal of Geophysical Research: Atmospheres, 119(18), 10619-10644.

Maidment, R.I., Grimes, D., Black, E., Tarnavsky, E., Young, M., Greatrex, H., Allan, R.P., Stein, T., Nkonde, E., Senkunda, S. and Alcántara, E.M.U. (2017) A new, long-term daily satellite-based rainfall dataset for operational monitoring in Africa. Scientific Data, 4, 170063.

Maidment, R.I., Grimes, D.I., Allan, R.P., Greatrex, H., Rojas, O. and Leo, O. (2012) Evaluation of satellite-based and model re-analysis rainfall estimates for Uganda. Meteorological Applications, 20(3), 308-317.

Makanzu, I.F., Ozer, P. and Moyersons, J. (2014) Caractéristiques des pluies et ravinement dans la ville de Kinshasa de 1961 à 2010. Liège: Colloque International La Géographie Physique et les Risques Naturels. Available at: http://orbi.ulg.ac.be/handle/2268/ 169520 [Accessed 25 April 2019].

Malhi, Y., Adu-Bredu, S., Asare, R.A., Lewis, S.L. and Mayaux, P. (2013) African rainforests: past, present and future. Philosophical Transactions of the Royal Society of London. Series B, Biological Sciences, 368, 20120312. https://doi.org/10.1098/rstb.2012.0312.

Maloba Makanga, J.D. (2009) Réseaux de mesures météorologiques au Gabon: pour quelle évaluation des changements climatiques? Annales de l'Université Omar Bongo, 14, 22.

Maussion, F., Scherer, D., Mölg, T., Collier, E., Curio, J. and Finkelnburg, R. (2014) Precipitation seasonality and variability over the Tibetan plateau as resolved by the high Asia reanalysis. Journal of Climate, 27, 1910-1927. https://doi.org/10.1175/JCLI-D-1300282.1.

McCollum, J.R., Gruber, A. and Ba, M.B. (2000) Discrepancy between gauges and satellite estimates of rainfall in equatorial Africa. Journal of Applied Meteorology, 39(5), 666-679.

Menne, M.J., Durre, I., Vose, R.S., Gleason, B.E. and Houston, T.G. (2012) An overview of the global historical climatology network-daily database. Journal of Atmospheric and Oceanic Technology, 29(7), 897-910.

Monsieurs, E., Kirschbaum, D.B., Tan, J., Maki Mateso, J.C., Jacobs, L., Plisnier, P.D., Thiery, W., Umutoni, A., Musoni, D., Mugaruka Bibentyo, T., Ganza, G.B., Ilombe, G., Bagalwa, L., Kankurize, C., Michellier, C., Stanley, T., Kervyn, F., Kervyn, M., Demoulin, A. and Dewitte, O. (2018) Evaluating TMPA rainfall over the sparsely gauged East African rift. Journal of Hydrometeorology, 19(9), 1507-1528.

Munzimi, Y., Hansen, M., Adusei, B. and Senay, G. (2015) Characterizing Congo Basin rainfall and climate using TRMM satellite data and limited raingauge ground observations. Journal of Applied Meteorology and Climatology, 54, 541-556.

Ndjendolé, S. and Pérard, J. (2003) Estimation et spatialisation des durées de retour des fortes pluies en Centrafrique. Publications de l'Association Internationale de Climatologie, 15, 319-325.

Negrón Juárez, R.I., Li, W., Fu, R., Fernandes, K. and de Oliveira Cardoso, A. (2009) Comparison of precipitation datasets over the tropical south American and African continents. Journal of Hydrometeorology, 10(1), 289-299.

Nicholson, S.E. and Dezfuli, A.K. (2013) The relationship of rainfall variability in western equatorial Africa to the tropical oceans and atmospheric circulation. Part I: The boreal spring. Journal of Climate, 26(1), 45-65.

Nicholson, S.E., Klotter, D., Dezfuli, A.K. and Zhou, L. (2018) New rainfall datasets for the Congo Basin and surrounding regions. Journal of Hydrometeorology, 19, 1379-1396.

Novella, N.S. and Thiaw, W.M. (2013) African rainfall climatology version 2 for famine early warning systems. Journal of Applied Meteorology and Climatology, 52(3), 588-606.

Ouédraogo, D.Y., Fayolle, A., Gourlet-Fleury, S., Mortier, F., Freycon, V., Fauvet, N., Rabaud, S., Cornu, G., Bénédet, F., Gillet, J.F., Oslisly, R., Doucet, J.L., Lejeune, P. and Favier, C. (2016) The determinants of tropical forest deciduousness: disentangling the effects of rainfall and geology in Central Africa. Journal of Ecology, 104(4), 924-935.

Pellarin, T., Louvet, S., Gruhier, C., Quantin, G. and Legout, C. (2013) A simple and effective method for correcting soil moisture and precipitation estimates using AMSR-E measurements. Remote Sensing of Environment, 136, 28-36.

Peterson, T.C. and Vose, R.S. (1997) An overview of the global historical climatology network temperature database. Bulletin of the American Meteorological Society, 78, 2837-2849.

Pombo, S., de Oliveira, R.P. and Mendes, A. (2015) Validation of remote-sensing precipitation products for Angola. Meteorological Applications, 22(3), 395-409.

Roca, R., Chambon, P., Jobard, I., Kirstetter, P.E., Gosset, M. and Bergès, J.C. (2010) Comparing satellite and surface rainfall products over West Africa at meteorologically relevant scales during the AMMA campaign using error estimates. Journal of Applied Meteorology and Climatology, 49(4), 715-731.

Roca, R., Taburet, N., Lorant, E., Chambon, P., Alcoba, M., Brogniez, H., Cloché, H., Dufour, C., Gosset, M. and Guilloteau, C. (2018) Quantifying the contribution of the Megha-Tropiques mission to the estimation of daily accumulated rainfall in the Tropics. Quarterly Journal of the Royal Meteorological Society, 144(S1), 49-63. https:// doi.org/10.1002/qj.3327.

Saatchi, S.S., Harris, N.L., Brown, S., Lefsky, M., Mitchard, E.T.A., Salas, W., Zutta, B.R., Buermann, W., Lewis, S.L., Hagen, S., Petrova, S., White, L., Silman, M. and Morel, A. (2011) Benchmark map of forest carbon stocks in tropical regions across three continents. Proceedings of the National Academy of Sciences, 108(24), 9899-9904.

Sahani, M., Moeyersons, J., Vandecasteele, I., Trefois, P. and Ozer, P. (2012) Evolution des caractéristiques pluviométriques dans la zone urbaine de Butembo (RDC) de 1957 à 2010. Geo-Eco-Trop: Revue Internationale de Géologie, de Géographie et d'Ecologie Tropicales, 36, 121-136.

Samba, G., Maloba Makanga, J.D. and Mbayi, R. (1999) Les saisons des pluies sur les plateaux Batéké et le plateau des Cataractes. Publications de l'Association Internationale de Climatologie, 12, 190-197.

Samba, G. and Nganga, D. (2012) Rainfall variability in Congo-Brazzaville: 1932-2007. International Journal of Climatology, 32(6), 854-873.

Scheel, M.L.M., Rohrer, M., Huggel, C., Santos Villar, D., Silvestre, E. and Huffman, G.J. (2011) Evaluation of TRMM multi-satellite precipitation analysis (TMPA) performance in the Central Andes region 
and its dependency on spatial and temporal resolution. Hydrology and Earth System Sciences, 15(8), 2649-2663.

Schumacher, C. and Houze, R.A., Jr. (2003) Stratiform rain in the Tropics as seen by the TRMM precipitation radar. Journal of Climate, 16(11), 1739-1756.

Serrat-Capdevila, A., Merino, M., Valdes, J.B. and Durcik, M. (2016) Evaluation of the performance of three satellite precipitation products over Africa. Remote Sensing, 8(10), 836.

Sylla, M.B., Giorgi, F., Coppola, E. and Mariotti, L. (2013) Uncertainties in daily rainfall over Africa: assessment of gridded observation products and evaluation of a regional climate model simulation. International Journal of Climatology, 33, 1805-1817. https://doi. org/10.1002/joc.3551.

Tang, G., Behrangi, A., Long, D., Li, C. and Hong, Y. (2018) Accounting for spatiotemporal errors of gauges: a critical step to evaluate gridded precipitation products. Journal of Hydrology, 559, 294-306.

Tesfamariam, B.G., Melgani, F. and Gessesse, B. (2019) Rainfall retrieval and drought monitoring skill of satellite rainfall estimates in the Ethiopian Rift Valley Lakes Basin. Journal of Applied Remote Sensing, 13(1), 014522. https://doi.org/10.1117/1.JRS.13.014522.

Thiemig, V., Rojas, R., Zambrano-Bigiarini, M., Levizzani, V. and De Roo, A. (2012) Validation of satellite-based precipitation products over sparsely gauged African River basins. Journal of Hydrometeorology, 13, 1760-1783. https://doi.org/10.1175/JHM-D-12-032. 1.

Toté, C., Patricio, D., Boogaard, H., van der Wijngaart, R., Tarnavsky, E. and Funk, C. (2015) Evaluation of satellite rainfall estimates for drought and flood monitoring in Mozambique. Remote Sensing, 7(2), 1758-1776.

Verhegghen, A., Mayaux, P., Wasseige, C.D. and Defourny, P. (2012) Mapping Congo Basin vegetation types from $300 \mathrm{~m}$ and $1 \mathrm{~km}$ multi-sensor time series for carbon stocks and forest areas estimation. Biogeosciences, 9(12), 5061-5079.

Vondou, D.A. and Haensler, A. (2017) Evaluation of simulations with the regional climate model REMO over Central Africa and the effect of increased spatial resolution. International Journal of Climatology, 37(S1), 741-760.
Ward, E., Buytaert, W., Peaver, L. and Wheater, H. (2011) Evaluation of precipitation products over complex mountainous terrain: a water resources perspective. Advances in Water Resources, 34(10), 1222-1231.

Washington, R., James, R., Pearce, H., Pokam, W.M. and Moufouma-Okia, W. (2013) Congo Basin rainfall climatology: can we believe the climate models? Philosophical Transactions of the Royal Society B: Biological Sciences, 368(1625), 20120296.

Wehbe, Y., Ghebreyesus, D., Temimi, M., Milewski, A. and Al Mandous, A. (2017) Assessment of the consistency among global precipitation products over the United Arab Emirates. Journal of Hydrology: Regional Studies, 12, 122-135.

Wilks, D.S. (2011) Statistical Methods in the Atmospheric Sciences. San Diego, CA: Academic Press.

World Meteorological Organization (2009). Handbook on CLIMAT and CLIMAT TEMP Reporting. WMO/TD-No. 1188, Geneva.

Xie, P. and Arkin, P.A. (1997) Global precipitation: a 17-year monthly analysis based on gauge observations, satellite estimates, and numerical model outputs. Bulletin of the American Meteorological Society, 78, 2539-2558.

Zhou, L., Tian, Y., Myneni, R.B., Ciais, P., Saatchi, S., Liu, Y., Piao, S., Chen, H., Vermote, E., Song, C. and Hwang, T. (2014) Widespread decline of Congo rainforest greenness in the past decade. Nature, 509(7498), 86-90.

How to cite this article: Camberlin P, Barraud G, Bigot S, Dewitte O, Makanzu Imwangana F, Maki Mateso J-C, Martiny N, Monsieurs E, Moron V, Pellarin T, Philippon N, Sahani M, Samba G. Evaluation of remotely sensed rainfall products over Central Africa. Q J R Meteorol Soc. 2019;1-24. https://doi.org/10.1002/qj.3547 